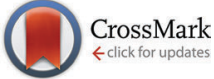

Cite this: Phys. Chem. Chem. Phys., 2014, 16, 21846

Received 2nd July 2014,

Accepted 20th August 2014

DOI: $10.1039 / \mathrm{c} 4 \mathrm{cp} 02884 \mathrm{~h}$

www.rsc.org/pccp

\section{Enhanced catalytic and supercapacitor activities of DNA encapsulated $\beta-\mathrm{MnO}_{2}$ nanomaterials $\dagger$}

\author{
Sivasankara Rao Ede, ${ }^{a}$ Ananthakumar Ramadoss, ${ }^{\text {b }}$ S. Anantharaj, \\ U. Nithiyanantham ${ }^{a}$ and Subrata Kundu*a
}

A new approach is developed for the aqueous phase formation of flake-like and wire-like $\beta-\mathrm{MnO}_{2}$ nanomaterials on a DNA scaffold at room temperature (RT) within a shorter time scale. The $\beta-\mathrm{MnO}_{2}$ nanomaterials having a band gap energy $\sim 3.54 \mathrm{eV}$ are synthesized by the reaction of $\mathrm{Mn}(I)$ salt with $\mathrm{NaOH}$ in the presence of DNA under continuous stirring. The eventual diameter of the $\mathrm{MnO}_{2}$ particles in the wire-like and flake-like morphology and their nominal length can be tuned by changing the DNA to Mn(I) salt molar ratio and by controlling other reaction parameters. The synthesized $\beta-\mathrm{MnO}_{2}$ nanomaterials exhibit pronounced catalytic activity in organic catalysis reaction for the spontaneous polymerization of aniline hydrochloride to emeraldine salt (polyaniline) at RT and act as a suitable electrode material in electrochemical supercapacitor applications. From the electrochemical experiment, it was observed that the $\beta-\mathrm{MnO}_{2}$ nanomaterials showed different specific capacitance $\left(C_{\mathrm{s}}\right)$ values for the flake-like and wire-like structures. The $C_{\mathrm{s}}$ value of $112 \mathrm{~F} \mathrm{~g}^{-1}$ at $5 \mathrm{mV} \mathrm{s}^{-1}$ was observed for the flake-like structure, which is higher compared to that of the wire-like structure. The flake-like $\mathrm{MnO}_{2}$ nanostructure exhibited an excellent long-term stability, retaining $81 \%$ of initial capacitance even after 4000 cycles, whereas for the wire-like $\mathrm{MnO}_{2}$ nanostructure, capacitance decreased and the retention value was only $70 \%$ over 4000 cycles. In the future, the present approach can be extended for the formation of other oxide-based materials using DNA as a promising scaffold for different applications such as homogeneous and heterogeneous organic catalysis reactions, $\mathrm{Li}$-ion battery materials or for the fabrication of other high performance energy storage devices.

\section{Introduction}

Over the last three decades, nanomaterials research has received increasing application in different interdisciplinary fields, such as catalysis, ${ }^{1}$ bio-medicine, ${ }^{2}$ nanoelectronics, ${ }^{3}$ sensing ${ }^{4}$ and energyrelated fields. ${ }^{5}$ This is because of their unique size-dependent properties, which are often thought of as a separate and intermediate state of matter lying between individual atom and bulk materials. Nanoparticles (NPs) are being investigated intensively, as they exhibit advantages due to their in size dependent catalytic, electronic and optical properties. Among different morphologies, one-dimensional (1-D) nanoscale building blocks,

\footnotetext{
${ }^{a}$ Electrochemical Materials Science (ECMS) Division, CSIR-Central Electrochemical Research Institute (CECRI), Karaikudi-630006, Tamil Nadu, India.

E-mail: skundu@cecri.res.in, kundu.subrata@gmail.com; Fax:+91-4565-227651; Tel: +91-4565-241487

${ }^{b}$ Nanomaterials and System Lab, Faculty of Applied Energy System, Science and Engineering College, Jeju National University, Jeju 690-756, Republic of Korea $\dagger$ Electronic supplementary information (ESI) available: The details such as instrumental specifications and preparations of samples for various characterizations are provided. The figures related to FE-SEM, EDS and LASER Raman studies are given. The table related to FTIR analyses are provided in Table T-1. See DOI: $10.1039 / \mathrm{c} 4 \mathrm{cp} 02884 \mathrm{~h}$
}

such as nanotubes, nanowires and nanorods, have attracted intensive interest because of their fundamental research and potential for wide-ranging applications. In general, two different routes are employed to access these ordered nanostructures: one is using a suitable template precursor, and the other is controlling selected parameters to organize the components into multidimensional morphologies.

Among the different oxide-based nanomaterials, manganese dioxide is one of the most attractive inorganic materials because of its physical and chemical properties and wide application in catalysis, molecular adsorption, biosensors, and particularly, in energy storage devices. ${ }^{6-9} \mathrm{MnO}_{2}$ exists in different polymorphic forms denoted $\alpha, \beta, \gamma$ and $\delta$, which differ according to various interconnection manner of the basic $\left[\mathrm{MnO}_{6}\right]$ octahedral units. ${ }^{10,11}$ The performance of $\mathrm{MnO}_{2}$ nanomaterials is strongly dependent on their morphology and crystallographic structures. Therefore, the formation of 1-D $\mathrm{MnO}_{2}$ nanomaterials utilizing an easy solution based on a wet-chemical route is extremely desired. The successful conjugation of nanomaterials with bio-molecules yields ordered nanoarchitectures where bio-molecules can be employed as a 'template' for a number of nanoscale materials. Among the different types of bio-molecules, deoxyribonucleic acid (DNA) has been used as an inexpensive, well-characterized, 
controllable and easily adaptable material with physical and chemical properties that can be explored to build inorganic nanostructures. ${ }^{12,13}$ DNA has unique molecular recognition and self-assembly capabilities because of its complementary base pairs. The properties of DNA have been exploited by a growing number of researchers ${ }^{14-16}$ to build advanced materials for energy storage, energy conversion devices, electronic circuits or even medical devices. Single-stranded DNA has been used for the fabrication of single-walled C-nanotubes (CNTs) by forming $\pi$-stacking between the DNA base pair and the carbon ring of CNTs. ${ }^{17}$ Apart from these, different types of metals, oxides or even semi-conductor nanowires like $\mathrm{Au},{ }^{18} \mathrm{Ag},{ }^{19} \mathrm{Pd},{ }^{20} \mathrm{Pt}^{21} \mathrm{Fe}_{2} \mathrm{O}_{3}{ }^{22}$ and $\mathrm{CdS}^{3,23}$ are organized on DNA templates. Thus, considering all these properties of DNA, which are derived from its base pairs and the abundant functional phosphate group on its hydrophilic phosphate-sugar backbone, further explorations of using DNA in the synthesis and assembly of advanced nanostructures is extremely desired and expected.

Different types of wet-chemical routes have been employed for the formation of $\mathrm{MnO}_{2}$ nanomaterials including hydrothermal, ${ }^{24}$ microemulsion, ${ }^{25}$ sol-gel, ${ }^{26}$ co-precipitation ${ }^{27}$ and microwave heating ${ }^{28}$ routes. Zheng et al. synthesized sea urchinlike $\mathrm{MnO}_{2}$ nanomaterials using a hydrothermal process. ${ }^{24} \mathrm{Pal}$ et al. synthesized spherical and rod-shaped $\mathrm{MnO}_{2}$ nanomaterials using wet-chemical techniques. ${ }^{29}$ There are several other reports where $\mathrm{MnO}_{2}$ was combined with other materials such as CNT and polymers and used in energy-related applications. ${ }^{30,31}$ Very recently, Ji et al. synthesized $\mathrm{MnO}_{2}$ nanofibers by electrospinning routes for energy-related applications. ${ }^{32}$ The transition metal oxides having variable oxidation states are considered as promising materials for supercapacitor electrodes and show excellent pseudo-capacitor behaviour. Among the various transition metal oxides, $\mathrm{MnO}_{2}$ is one of the most studied active materials for pseudo-capacitors because of its low cost, high positive electrode potential and relatively low molecular weight. ${ }^{33,34}$ However, the poor stability presented after just a few charge-discharge cycles is a crucial limitation for practical application of $\mathrm{MnO}_{2}$. Moreover, the electrochemical and catalysis properties of $\mathrm{MnO}_{2}$ are strongly dependent on its dimensions, morphology and crystalline structure. Most of the reports described above for the synthesis of $\mathrm{MnO}_{2}$ nanomaterials need either high temperature, long processing time, or utilization of surfactant; otherwise, the process produces mixture of multishaped particles. Therefore, the development of facile, mild, room temperature (RT) and cost-effective routes for creating novel morphologies is a key scientific challenge.

In this report, we present for the first time the synthesis of different morphologies of the $\beta-\mathrm{MnO}_{2}$ nanomaterials at room temperature (RT) using DNA as a scaffold. The $\beta-\mathrm{MnO}_{2}$ nanomaterials having band gap energy $\sim 3.54 \mathrm{eV}$ are synthesized by the reaction of $\mathrm{MnCl}_{2}$ with $\mathrm{NaOH}$ in presence of DNA under continuous stirring for $\sim 2$ hours. Different morphologies of the $\beta-\mathrm{MnO}_{2}$ nanomaterials, such as flake-like and wire-like nanomaterials, can be synthesized simply by controlling the DNA to Mn(II) salt molar ratio and by controlling other reaction parameters. The synthesized $\beta-\mathrm{MnO}_{2}$ nanomaterials exhibit as an excellent material in organic catalysis reactions for the spontaneous polymerization of aniline hydrochloride to emeraldine salt (polyaniline) at room temperature that can act as a suitable electrode material in electrochemical supercapacitor applications. From the electrochemical supercapacitor experiments, it was found that the $\beta-\mathrm{MnO}_{2}$ nanomaterials on DNA shows different specific capacitance $\left(C_{\mathrm{s}}\right)$ values for the flake-like and wire-like morphology and the order of $C_{\mathrm{s}}$ values are as follows: flake-like $>$ wire-like. The $C_{\mathrm{s}}$ of $112 \mathrm{~F} \mathrm{~g}^{-1}$ at $5 \mathrm{mV} \mathrm{s}^{-1}$ was observed for $\beta-\mathrm{MnO}_{2}$ with a flake-like structure. The proposed synthesis route is simple, less time-consuming than others, and cost effective.

\section{Experimental section}

\section{Reagents and instruments}

Double-stranded herring testes DNA with an average molecular weight $\sim 50$ kbps (base pairs) was purchased from Sigma-Aldrich. The manganese(II) chloride $\left(\mathrm{MnCl}_{2} \cdot 4 \mathrm{H}_{2} \mathrm{O}\right)$ and sodium hydroxide $(\mathrm{NaOH})$ were also purchased from Sigma-Aldrich and used as received. Aniline hydrochloride was purchased from Alfa Aser, India. Sodium sulfate $\left(\mathrm{Na}_{2} \mathrm{SO}_{4}\right)$, carbon black, 1-methyl-2-pyrrolidinone (NMP) and polyvinylidene fluoride (PVDF) were obtained from Alfa Aesar. Absolute ethyl alcohol $\left(\mathrm{CH}_{3} \mathrm{CH}_{2} \mathrm{OH}\right)$ was obtained from ChangshuYangyuan Chemical, China. De-ionized (DI) water was used for the entire synthesis and application purposes. The synthesized DNA-encapsulated $\beta-\mathrm{MnO}_{2}$ nanomaterials were characterized using several spectroscopic techniques, such as UV-Visible (UV-Vis) absorption spectra, transmission electron microscopy (TEM) analysis, field emission scanning electron microscopy (FE-SEM) analysis, energy dispersive X-ray spectroscopy (EDS) analysis, X-ray diffraction (XRD) analysis, LASER Raman measurements, X-ray photoelectron spectroscopic (XPS) analysis, Fourier transform infrared (FT-IR) spectroscopy analysis and a ${ }^{1} \mathrm{H}$ NMR study. The detailed specifications of these instruments are given in the ESI. $\dagger$

\section{Room temperature formation of $\beta-\mathrm{MnO}_{2}$ nanomaterials on DNA scaffold}

A stock DNA solution $(0.06 \mathrm{gm} / 50 \mathrm{~mL})$ was prepared by dissolving measured amounts of highly pure herring testes DNA with $\mathrm{DNA}_{\mathrm{se}}$ - and $\mathrm{RNA}_{\mathrm{se}}$-free DI water. After weighing, the DNA was mixed with DI water and stirred overnight using a magnetic stirrer to yield a homogeneous solution. In a typical synthesis, $20 \mathrm{~mL}$ of DNA solution was mixed with $2.5 \mathrm{~mL}$ of $0.02 \mathrm{M}$ aqueous $\mathrm{MnCl}_{2}$ solution and stirred well for 10-15 minutes. A light white or opaque color appeared after 10-15 minutes of stirring. Then, $2.5 \mathrm{~mL}$ of $0.1 \mathrm{M}$ aqueous $\mathrm{NaOH}$ solution was added slowly while stirring. The color of the solution changed to pale brown initially after addition of $\mathrm{NaOH}$, but it became dark brown after completion of the reaction. The total reaction time took $\sim 2$ hours. The solution exclusively contained $\beta-\mathrm{MnO}_{2}$ with a flake-like structure. Another morphology of the $\beta-\mathrm{MnO}_{2}$ nanomaterials was prepared by changing the concentration ratio of DNA to Mn(II) salt and changing other reaction parameters. 

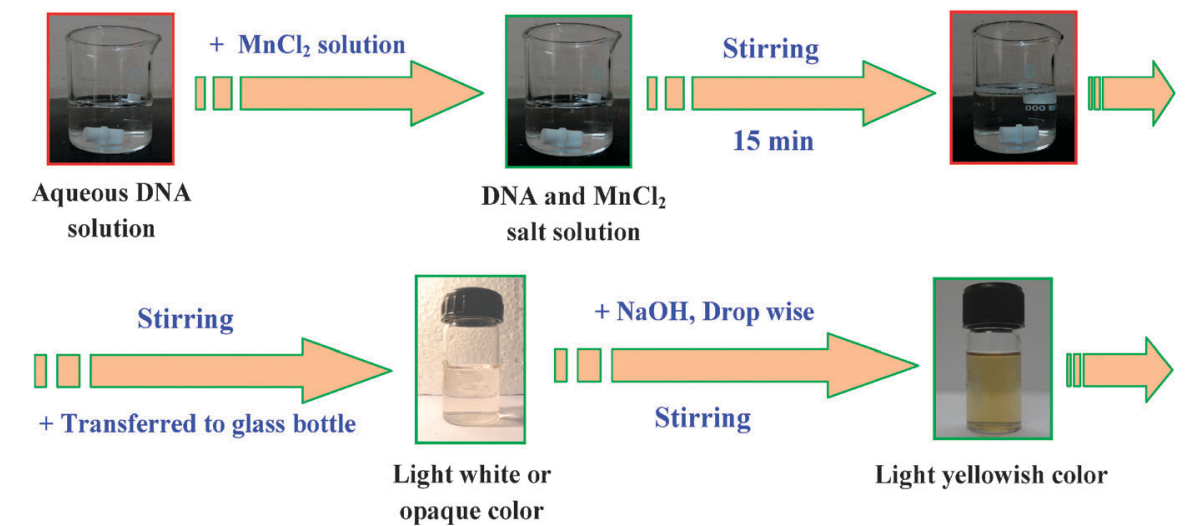

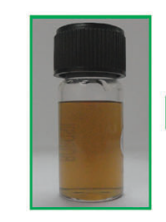

Light brownish color

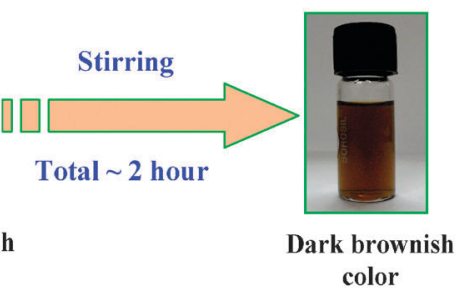

Shape-selective DNA- $\mathrm{MnO}_{2}$

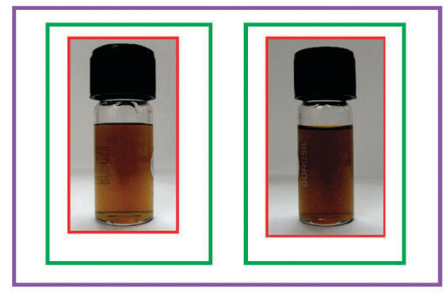

Wire-like Flake-like

Scheme 1 The step-wise formation of the DNA-MnO ${ }_{2}$ nanomaterials are schematically shown in Scheme 1.

Table 1 The detailed final concentrations of all the reaction parameters, time of reaction, particles size, shape etc. are summarized in Table 1

\begin{tabular}{|c|c|c|c|c|c|c|c|}
\hline $\begin{array}{l}\text { Set } \\
\text { number }\end{array}$ & $\begin{array}{l}\text { Final conc. } \\
\text { of DNA }(\mathrm{M})\end{array}$ & $\begin{array}{l}\text { Final conc. of } \\
\mathrm{MnCl}_{2} \text { salt }(\mathrm{M})\end{array}$ & $\begin{array}{l}\text { Final conc. } \\
\text { of } \mathrm{NaOH}(\mathrm{M})\end{array}$ & $\begin{array}{l}\text { Total time of reaction/ } \\
\text { stirring (hour) }\end{array}$ & $\begin{array}{l}\text { Color of the } \mathrm{MnO}_{2} \\
\text { solutions, } \lambda_{\max } \text { values }\end{array}$ & $\begin{array}{l}\text { Shape of } \\
\text { the particles }\end{array}$ & $\begin{array}{l}\text { Average diameter of } \\
\text { the particles }(\mathrm{nm})\end{array}$ \\
\hline 1 & $2.1 \times 10^{-2}$ & $2.3 \times 10^{-3}$ & $4.4 \times 10^{-3}$ & 2 & Dark brown & Wire-like & $\begin{array}{l}\text { Length } \sim 1.9 \pm 0.2 \mu \mathrm{m} \\
\text { and diameter } \sim 35 \pm 5 \mathrm{~nm}\end{array}$ \\
\hline
\end{tabular}

The overall experiment was done at room temperature $\sim 28{ }^{\circ} \mathrm{C}$ and the total reaction time was $\sim 2$ hour. The step-wise formation of DNA- $\mathrm{MnO}_{2}$ nanomaterials is shown in Scheme 1 and the final concentration of different reagents, reaction time, size and shape of the particles are summarized in Table 1 . The synthesized DNA-encapsulated $\beta-\mathrm{MnO}_{2}$ nanomaterials were characterized using UV-Vis, TEM, EDS, XRD, Raman, XPS and FTIR analysis; the details of the sample preparation procedure for various characterizations are given in ESI. $\dagger$

\section{Electrode fabrication for electrochemical supercapacitor study}

Electrochemical measurements were carried out using a conventional three-electrode system. The synthesized $\mathrm{DNA}-\mathrm{MnO}_{2}$ samples, platinum and $\mathrm{Ag} / \mathrm{AgCl}$ were used as the working, counter and reference electrodes, respectively. The working electrode was prepared by mixing $80 \mathrm{wt} \%$ of the prepared samples, $10 \mathrm{wt} \%$ of carbon black and $10 \mathrm{wt} \%$ of polyvinylidene fluoride (PVDF). These materials were dispersed in 1-methyl-2pyrrolidinone (NMP), and the resultant slurry was coated on the nickel foam current collector. After that, the electrode was dried at $90{ }^{\circ} \mathrm{C}$ for $24 \mathrm{~h}$ to evaporate the solvent. The entire test was done in $1 \mathrm{M} \mathrm{Na}_{2} \mathrm{SO}_{4}$ aqueous solution at ambient temperature.
EIS measurements were studied in the frequency range from $100 \mathrm{kHz}$ to $0.1 \mathrm{~Hz}$ at the open circuit potential with an amplitude of $10 \mathrm{mV}$. Cyclic voltammetry and galvanostatic charge-discharge techniques were measured in the potential range from 0 to $0.8 \mathrm{~V}$ at various scan rates $\left(5,10,25,50,75,100\right.$ and $\left.125 \mathrm{mV} \mathrm{s}^{-1}\right)$ and current densities $\left(0.1,0.2,0.4,0.6,0.8\right.$ and $\left.1 \mathrm{~mA} \mathrm{~cm}^{-2}\right)$, respectively. The specific capacitance of the electrodes was calculated from the CV curves using the following equation: ${ }^{35}$

$$
C_{\mathrm{s}}=\frac{\int i \Delta V}{v m \Delta V}
$$

where $\int i \Delta V$ is the integral area of the CV curves; $v$ is the scan rate; $m$ is the mass of the active material; and $\Delta V$ is the operating voltage window.

The specific capacitance of the electrodes was also calculated from the GCD method using the following equation: ${ }^{35}$

$$
C_{\mathrm{s}}=\frac{I \Delta t}{m \Delta V}
$$

where $I$ is the constant discharge current; $\Delta t$ is the discharge time; $m$ is the mass of the electroactive material; and $\Delta V$ is the potential window. 


\section{Results and discussion}

\section{UV-Vis spectroscopic analysis}

Fig. 1A shows the room temperature UV-Vis absorption spectra of the different solution mixtures for the formation of DNAencapsulated $\beta-\mathrm{MnO}_{2}$ nanomaterials. Curve a, Fig. 1A shows the absorption band of DNA-only solution, which has a $\lambda_{\max }$ at $258 \mathrm{~nm}$ due to the presence of an aromatic base molecules on its structure. Curve b, Fig. 1A shows the absorption band of aqueous $\mathrm{MnCl}_{2}$ solution that has two bands; one is less intense at lower wavelength regions at $\sim 223 \mathrm{~nm}$ and other is more intense at $\sim 296 \mathrm{~nm}$. These bands are due to ligand-to-metal charge transfer (LMCT) spectra. Similar types of LMCT bands were observed for the Au salt. ${ }^{36}$ Curve c shows the absorption bands of the mixture of DNA, $\mathrm{MnCl}_{2}$ and $\mathrm{NaOH}$ (just after mixing),
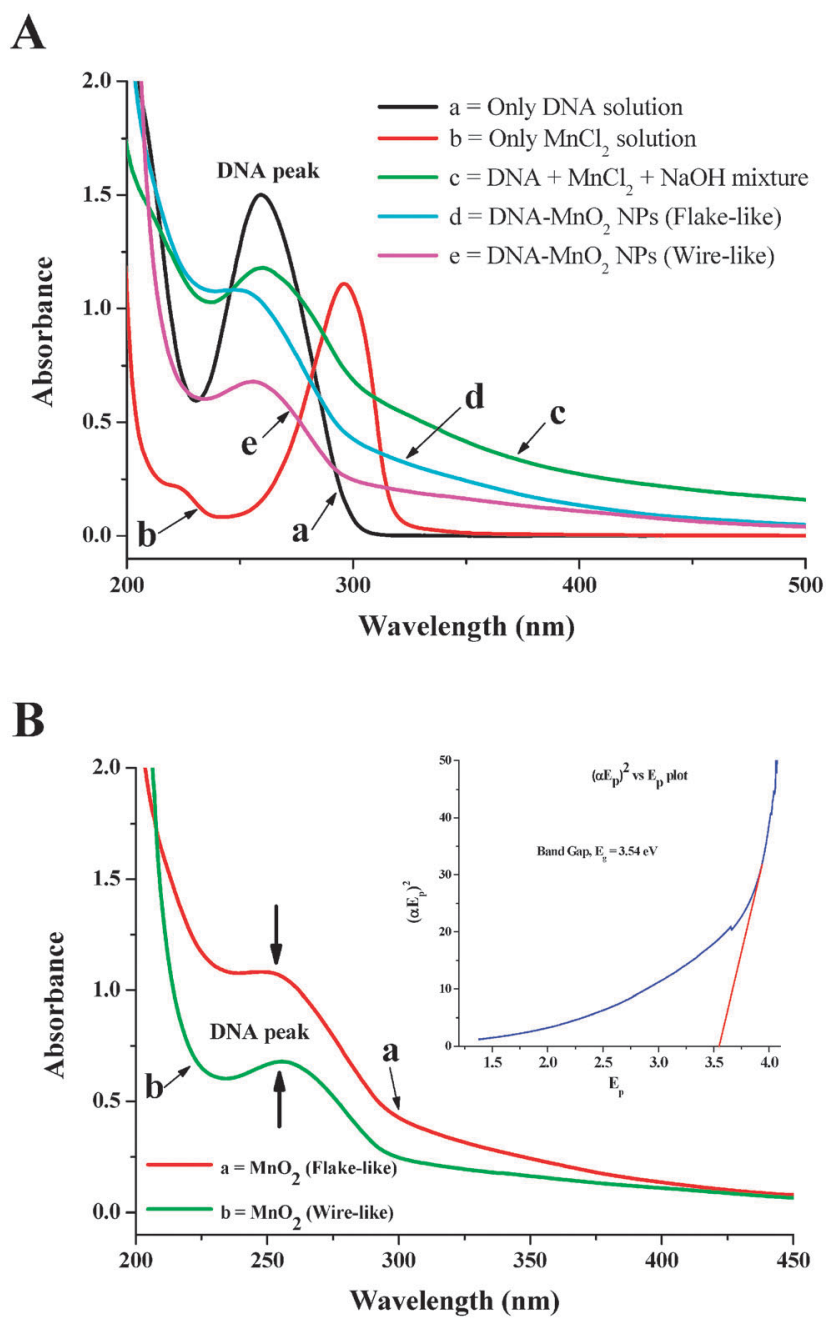

Fig. 1 (A) UV-Vis spectrum of the different solution mixtures for the preparation of $\beta-\mathrm{MnO}_{2}$ nanomaterials on a DNA scaffold. Curve (a) shows the absorption band of aqueous DNA solution only; (b) shows the absorption band of aqueous $\mathrm{MnCl}_{2}$ salt solution; (c) shows the absorption band of the mixture of DNA, Mn(॥) salt and $\mathrm{NaOH}$ solution; (d) and (e) show the absorption band for $\mathrm{MnO}_{2}$ particles on DNA having flake-like and wire-like shapes. (B) The enlarged absorption band of the $\mathrm{DNA}-\mathrm{MnO}_{2}$ nanomaterials having flake-like and wire-like shape. The inset of (B) shows the plot of $\left(\alpha E_{p}\right)^{2}$ versus $\left(E_{p}\right)$. which shows a band at $260 \mathrm{~nm}$ (due to DNA) and a new broad band in the range 300 to $380 \mathrm{~nm}$ due to interaction of $\mathrm{Mn}$ (II) ions with DNA or reaction of the $\mathrm{Mn}$ (II) salt with $\mathrm{NaOH}$. The original DNA peak has been shifted a few nm, indicating its interaction with the metal salt. Curves $d$ and e show the absorption band due to the evolution of $\mathrm{MnO}_{2}$ NPs on DNA with flake-like and wire-like morphologies, respectively. Both the spectra show similar types of spectral features, although the parent DNA peak position has been shifted. Fig. 1B shows the enlarged absorption band of the $\mathrm{DNA}-\mathrm{MnO}_{2}$ nanomaterials, which have been shown in curves $d$ and e in Fig. 1A. From the curves $\mathrm{a}$ and $\mathrm{b}$ in Fig. $1 \mathrm{~B}$, it is observed that the DNA peak appears at $250 \mathrm{~nm}$ and $254 \mathrm{~nm}$ for the flake-like and wire-like morphologies, respectively. In all the cases, the parent DNA peak is shifted $\sim 5$ to $10 \mathrm{~nm}$ due to its attachment with $\mathrm{MnO}_{2}$ particles. The absorption band observed for $\mathrm{MnO}_{2}$ is in agreement with a previous report. ${ }^{37}$ The excitonic transition of $\mathrm{MnO}_{2}$ nanomaterials was also determined; the theoretical expression for the determination of band gap of semi-conductor materials is given elsewhere. ${ }^{38}$ The well-known Tauc approach was used to determine the band gap $\left(E_{\mathrm{g}}\right)$ and the plot of $\left(\alpha E_{\mathrm{p}}\right)^{2}$ versus $\left(E_{\mathrm{p}}\right)$ based on direct transition; the corresponding extrapolated value of $E_{\mathrm{p}}$ at $\alpha=0$ gives the absorption edge energy that is the corresponding band gap of $\mathrm{MnO}_{2}$ nanomaterials. The inset of Fig. 1B shows the plot of $\left(\alpha E_{\mathrm{p}}\right)^{2}$ versus $\left(E_{\mathrm{p}}\right)$; the observed band gap for $\beta-\mathrm{MnO}_{2}$ nanomaterials is $3.54 \mathrm{eV}$. In both the morphologies, we have observed almost similar band gap energy and a blue shift in the absorption edge of the $\mathrm{MnO}_{2}$ nanomaterials compared to bulk $\mathrm{MnO}_{2}$ is because of the presence of smaller size $\mathrm{MnO}_{2}$ particles; this is in agreement with the quantum confinement effect.

\section{Transmission Electron Microscopy (TEM) analysis}

Fig. 2 shows the transmission electron microscopy (TEM) images of the $\beta-\mathrm{MnO}_{2}$ nanomaterials on DNA scaffold. Fig. 2A and $\mathrm{B}$ show the low and high magnification TEM images of the $\beta-\mathrm{MnO}_{2}$ nanomaterials having flake-like structure corresponding to curve $d$ in Fig. 1A. From the image it can be seen that the nominal length of the nano-flakes is $\sim 275 \pm 25 \mathrm{~nm}$ and the average diameter is $\sim 25 \pm 5 \mathrm{~nm}$. The inset of Fig. 2A shows the corresponding high magnified image and the inset of Fig. 2B shows the corresponding selected area electron diffraction (SAED) pattern. The SAED pattern demonstrates that the particles are crystalline in nature. Fig. $2 \mathrm{C}$ and $\mathrm{D}$ show the low and high magnification TEM images of the $\beta-\mathrm{MnO}_{2}$ nanomaterials having wire-like morphology corresponding to curve e in Fig. 1A. From the image it can be seen that the length of the wires is $\sim 1.9 \pm 0.2 \mu \mathrm{m}$ and the average diameter of the wires is $\sim 35 \pm 5 \mathrm{~nm}$. Careful observation of the FE-SEM analysis says that the $\mathrm{DNA}-\mathrm{MnO}_{2}$ wires are composed of smaller size aggregated spherical particles, as shown in Fig. S1 in the ESI. $\dagger$ The $\mathrm{MnO}_{2}$ particles grow along the DNA chain and generate the wire-like morphologies. The inset of Fig. 2D shows the corresponding SAED pattern. The SAED pattern shows that the particles are crystalline in nature. The TEM analysis confirmed that the present synthesis route generates different morphologies of $\beta-\mathrm{MnO}_{2}$ nanomaterials. 

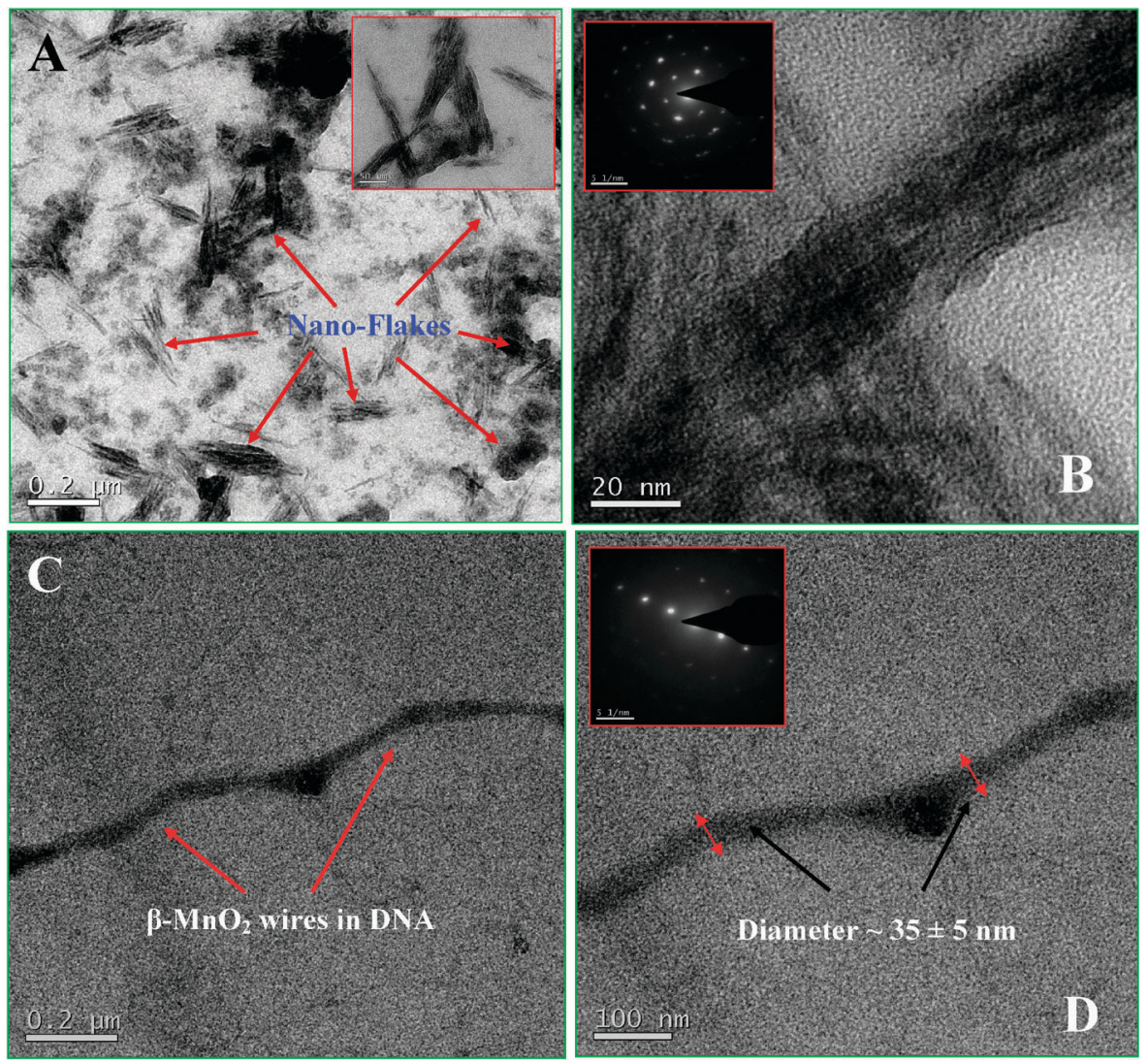

Fig. 2 Transmission electron microscopy (TEM) images of the $\beta-\mathrm{MnO}_{2}$ nanomaterials on a DNA scaffold. (A), and (B) show the low and high magnification TEM images of the DNA- $\mathrm{MnO}_{2}$ nanomaterials having the flake-like shape. The inset of (A) shows corresponding high magnification image, and the inset of (B) shows the SAED pattern. (C) and (D) show the low and high magnification TEM images of DNA-MnO 2 nanomaterials having the wire-like shape, respectively. The inset of (D) shows corresponding SAED pattern.

\section{Energy Dispersive X-ray Spectroscopy (EDS) and X-ray Diffraction (XRD) analysis}

Fig. S2 (ESI $\dagger$ ) shows the (EDS) analysis, which confirms the elements present in the synthesized $\mathrm{DNA}-\mathrm{MnO}_{2}$ nanomaterials. The EDS spectrum consists of different peaks for C, N, O, Mn, Na, $\mathrm{Si}$ and P. The Na peak is either from the DNA or from the $\mathrm{NaOH}$ solution used in our synthesis. The Si peak is from the glass substrate used to deposit the $\mathrm{MnO}_{2}$ nanomaterials for EDS analysis. The $\mathrm{N}$ and $\mathrm{P}$ peaks are from the DNA molecule. The $\mathrm{Mn}$ peak is from the $\mathrm{MnO}_{2}$ nanomaterial, and the O peak is either from $\mathrm{MnO}_{2}$, DNA or from $\mathrm{NaOH}$. The EDS analysis confirms that the $\mathrm{MnO}_{2}$ nanomaterials are formed and stabilized by the DNA molecule. Fig. 3 shows the XRD pattern of the DNA- $\mathrm{MnO}_{2}$ nanomaterials having flake-like morphology. Here we obtained the XRD pattern for only the flake-like shape, although the wire-like morphology was also examined (not shown here). XRD analysis was used to examine the phase and purity of the product. All the diffraction peaks were indexed; the corresponding $2 \theta$ values are $38.4^{\circ}$ for (101), $44.8^{\circ}$ for (111), $46.4^{\circ}$ for $(210), 57.4^{\circ}$ for (211), 66.9 for (310) planes. All the diffraction peaks nicely match with a pure tetragonal phase of $\beta-\mathrm{MnO}_{2}$ having JCPDS card number 24-0735, with $a=4.39 \AA$ and $c=2.87 \AA$ Å having space group $P 4_{2} / \mathrm{mnm}^{29,39}$ The observed sharp XRD pattern is because of the presence of smaller size $\mathrm{MnO}_{2}$ particles, as observed from the

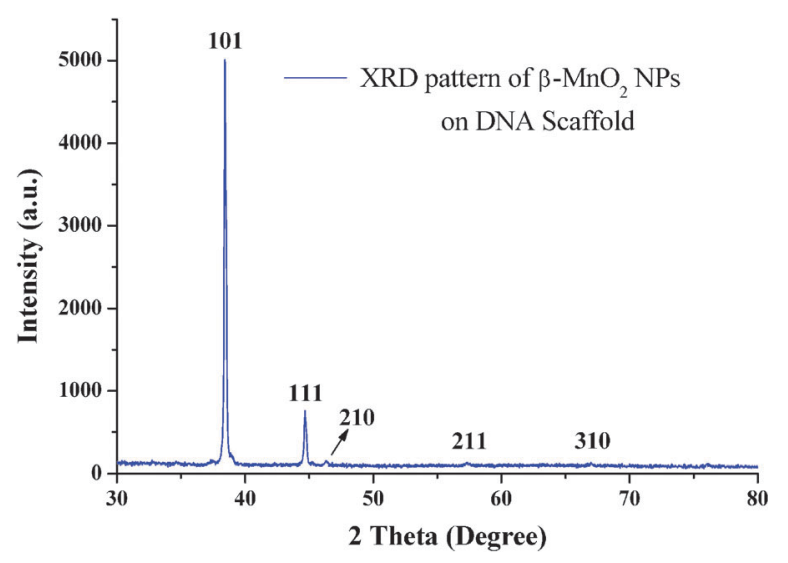

Fig. 3 X-ray diffraction pattern of the flake-like $\beta-\mathrm{MnO}_{2}$ nanomaterials on a DNA scaffold.

FE-SEM analysis (shown in ESI $\dagger$ ). No other peaks were observed for other phases, which indicate the high purity and high crystallinity of the synthesized DNA- $\mathrm{MnO}_{2}$ nanomaterials.

\section{X-ray Photoelectron Spectroscopic (XPS) studies}

Fig. 4 shows the X-ray photoelectron spectroscopy (XPS) analysis of the synthesized DNA-MnO${ }_{2}$ nanomaterials. The XPS analysis 
A
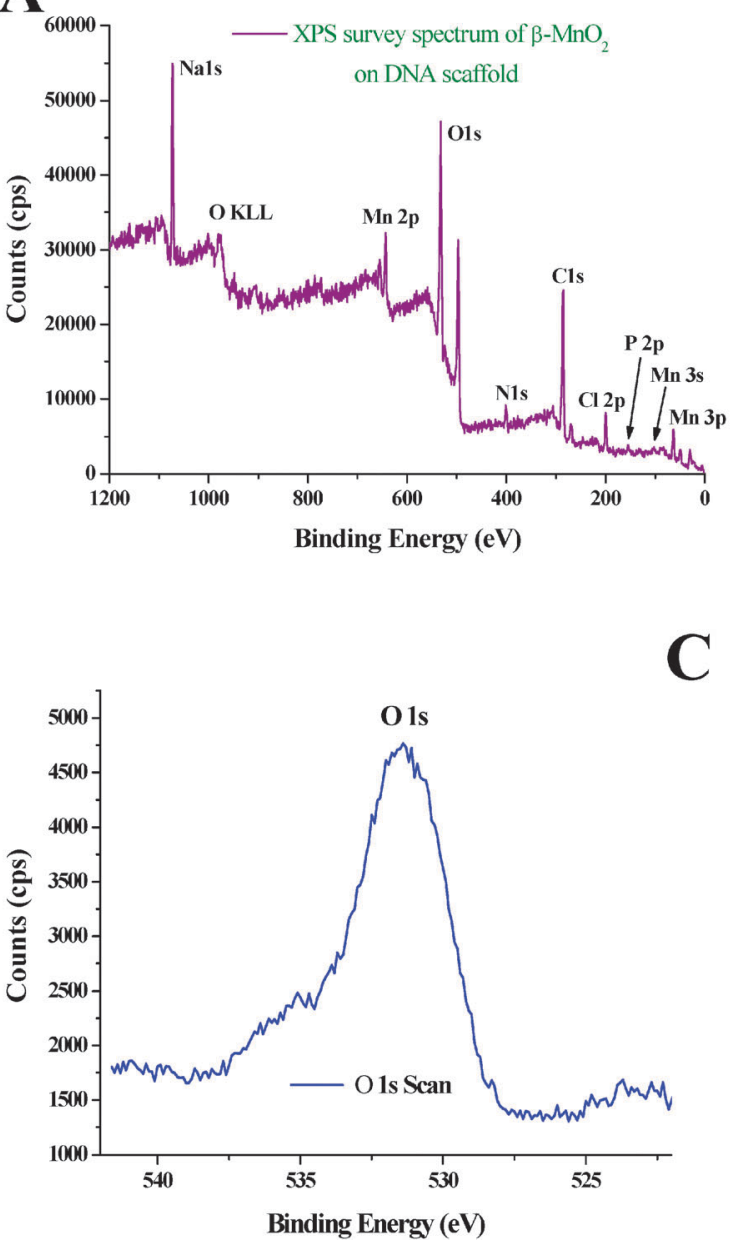

B

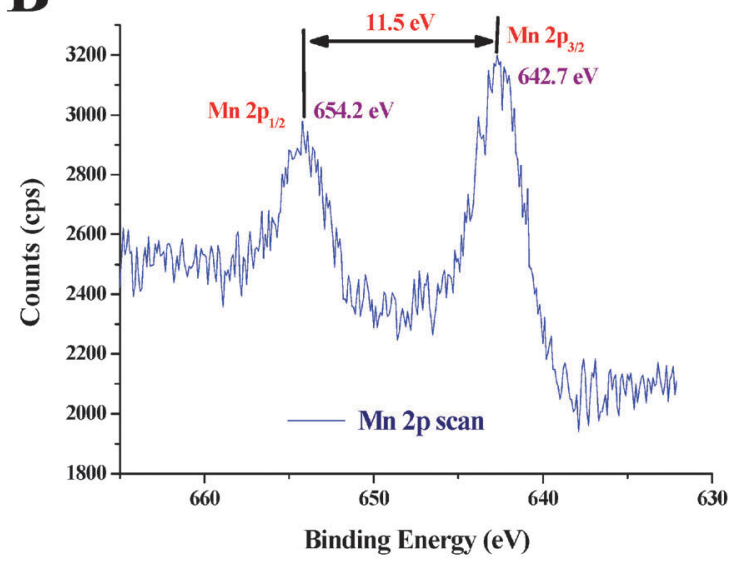

D

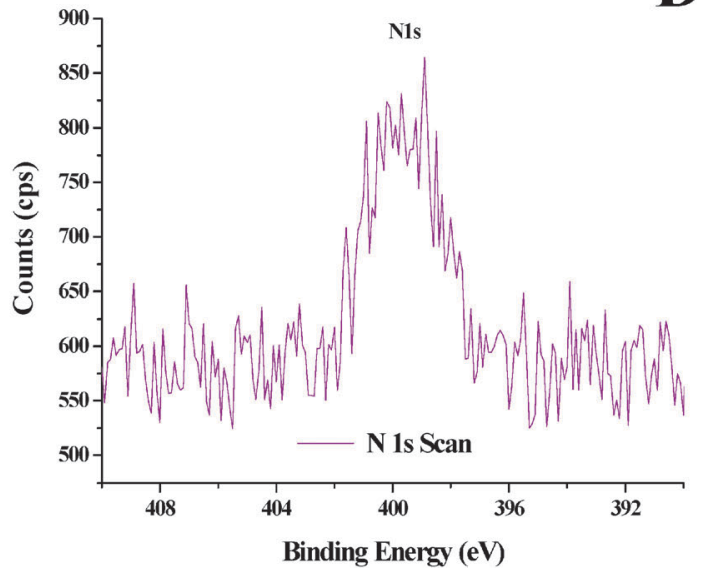

Fig. 4 X-ray photoelectron spectroscopy (XPS) analysis of the synthesized DNA- $\mathrm{MnO}_{2}$ nanomaterials. (A) shows the XPS survey scan, which consists of different peaks due to Na 1s, O KLL, Mn 2p, O 1s, N 1s, C 1s, Cl 2p, P 2p, Mn 3s and Mn 3p. (B), (C) and (D) show the high resolution scan for Mn 2p, O 1s and $\mathrm{N}$ 1s, respectively.

was preliminarily performed to check the oxidation state of the elements present in the materials. Fig. 4A shows the XPS survey scan, which consists of different peaks due to Na 1s, O KLL, Mn 2p, O 1s, N 1s, C 1s, Cl 2p, P 2p, Mn 3s and Mn 3p. The $\mathrm{Na}$ 1s and P 2p peaks is from the DNA molecule, which further confirms the capping of DNA molecule on the $\mathrm{MnO}_{2}$ NPs surface. The high resolution scan of the $\mathrm{Mn} 2 \mathrm{p}, \mathrm{O} 1 \mathrm{~s}$ and $\mathrm{Na}$ 1s is shown in Fig. 4B, C and D, respectively. From Fig. 4B, the peak at $654.2 \mathrm{eV}$ and $642.7 \mathrm{eV}$ signifies the atomic properties of the Mn $2 \mathrm{p}_{1 / 2}$ and a Mn $2 \mathrm{p}_{3 / 2}$ state that appears because of spin orbit coupling. The peak separation between the Mn $2 \mathrm{p}_{1 / 2}$ and $\mathrm{Mn} 2 \mathrm{p}_{3 / 2}$ states is $\sim 11.5 \mathrm{eV}$. The binding energy values at a specific position of $\mathrm{Mn}$ indicate the existence of a $\mathrm{Mn}(\mathrm{rv})$ oxidation state in the entire product. Similar types of XPS pattern for the Mn 2p state have been previously observed by other researchers. ${ }^{29,33}$ The band at $531.3 \mathrm{eV}$ is attributed to the O 1s binding energy, as shown in Fig. 4C. The band at $399.7 \mathrm{eV}$ is attributed to the $\mathrm{N} 1 \mathrm{~s}$ binding energy, which is from the DNA molecule only, as seen in Fig. 4D. This indicates that the $\mathrm{Mn}$ is the $\mathrm{Mn}(\mathrm{Iv})$ state in the entire product.

\section{LASER Raman and Thermal Analysis (TGA-DTA) studies}

The LASER Raman spectra of the $\beta-\mathrm{MnO}_{2}$ nanomaterials are shown in Fig. S3 in the ESI. $\dagger$ As an example, we show the Raman spectrum of the flake-like structure, although the spectrum for wire-like morphology was also recorded. The Raman spectrum of $\beta-\mathrm{MnO}_{2}$ nanomaterial show one sharp peak at $645 \mathrm{~cm}^{-1}$ and another low intensity peak at $350 \mathrm{~cm}^{-1}$. The high intensity Raman peak corresponds to the stretching mode of $\mathrm{MnO}_{6}$ octahedra, and the low intensity peaks at the lower wavenumber region are attributed to the deformation modes of the metaloxygen chain of $\mathrm{Mn}-\mathrm{O}-\mathrm{Mn}$ in $\mathrm{MnO}_{2}$ octahedra lattice. A similar type of LASER Raman spectrum has been previously reported for $\beta-\mathrm{MnO}_{2}$ nanomaterials. ${ }^{29}$ It is important to note that a very low LASER power is required to get the desired spectra, as the synthesized DNA- $\mathrm{MnO}_{2}$ material is very prone to degradation due to LASER aggression. The approximate mass loading of $\mathrm{MnO}_{2}$ on the DNA- $\beta-\mathrm{MnO}_{2}$ nanomaterials was measured by thermogravimetric analysis (TGA) and differential thermal analysis (DTA) studies. The as-prepared DNA- $\beta-\mathrm{MnO}_{2}$ nanomaterials are 


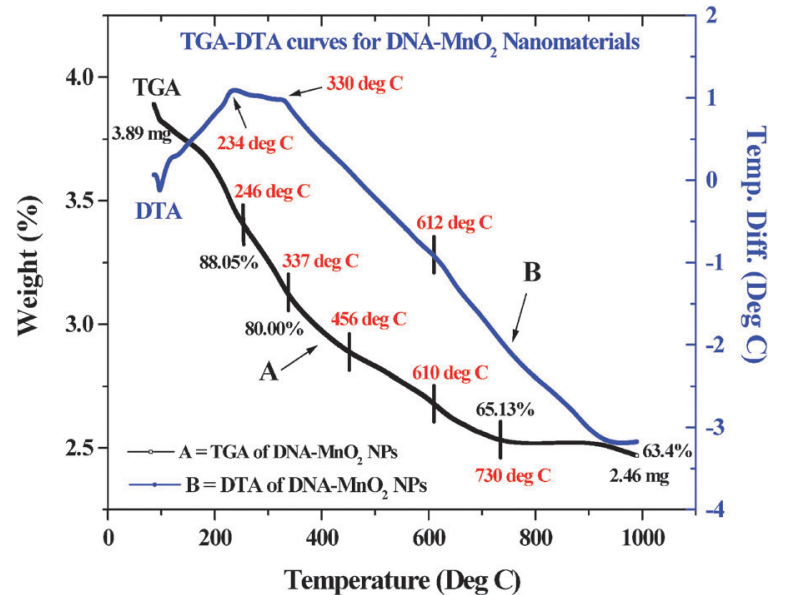

Fig. 5 Thermogravimetric analysis (TGA, curve A) and differential thermal analysis (DTA, curve B) of the DNA- $\beta-\mathrm{MnO}_{2}$ nanomaterials.

heated from RT to $1000{ }^{\circ} \mathrm{C}$ with an increment of $10{ }^{\circ} \mathrm{C} \mathrm{min}^{-1}$ in air. Fig. 5A and B show the TGA and DTA curve of the DNA$\beta-\mathrm{MnO}_{2}$ nanomaterials, respectively. A continuous weight loss due to the dehydration of the adsorbed and lattice water is observed from the samples, and an endothermic peak was observed near $100{ }^{\circ} \mathrm{C}$ because of loss of water, which was physically adsorbed. The other weight loss takes place above $120^{\circ} \mathrm{C}$ to below $360{ }^{\circ} \mathrm{C}$; it is because of the removal of the excess DNA molecule attached with, or present in, the nanomaterial samples. Above $400{ }^{\circ} \mathrm{C}$ to $1000{ }^{\circ} \mathrm{C}$, the weight loss can be attributed to the slow decomposition of $\mathrm{MnO}_{2}$ at high temperatures. Thus, the actual loading of $\mathrm{MnO}_{2}$ based on the TGA profiles at $246{ }^{\circ} \mathrm{C}$ is $88 \%$, $456{ }^{\circ} \mathrm{C}$ is $74 \%, 730{ }^{\circ} \mathrm{C}$ is $65 \%$ and at the end of the process it is $63.43 \%$. From curve A, we observe that the analysis was started with $3.89 \mathrm{mg}$ of sample, and after complete heating up to $1000{ }^{\circ} \mathrm{C}$, the sample remained was $2.46 \mathrm{mg}$. Thus, the percentage weight loss for our analysis up to $1000{ }^{\circ} \mathrm{C}$ is $36.76 \%$. From the DTA curve at Fig. 5B, the two sharp exothermic peaks appear at $234{ }^{\circ} \mathrm{C}$ and $330{ }^{\circ} \mathrm{C}$ might be due to a change in crystallinity or possibly due to a phase change in the material.

\section{Fourier transforms infrared (FT-IR) spectroscopic analysis}

Fig. 6 shows the combined FT-IR spectra of the DNA itself and DNA bounded nanomaterials at a wavenumber scale of 4000 to $400 \mathrm{~cm}^{-1}$. In Fig. 5, curve A denotes the FTIR spectrum of DNA only and curve B denotes the FTIR spectrum of DNA-bounded $\mathrm{MnO}_{2}$ particles. As an example, we examined here the FTIR spectrum of flake-like $\mathrm{MnO}_{2}$ particles, the other shape also give a similar type of spectral pattern. FTIR spectroscopy is well known for its high sensitivity for detecting both inorganic and organic species at trace levels. The comparison of spectrum A and spectrum B in Fig. 6 indicates the presence of DNA in the $\mathrm{MnO}_{2}$ nanomaterials and the possible interaction between them. In curve A, for DNA only, the peaks at lower wave number region at $560 \mathrm{~cm}^{-1}, 821 \mathrm{~cm}^{-1}, 1108-1213 \mathrm{~cm}^{-1}$ and $1281 \mathrm{~cm}^{-1}$ indicate the deoxyribose region and stretching vibration due to the phosphate groups in DNA. These specific peaks are either shifted, weak or not visible in case of DNA-bounded $\mathrm{MnO}_{2}$

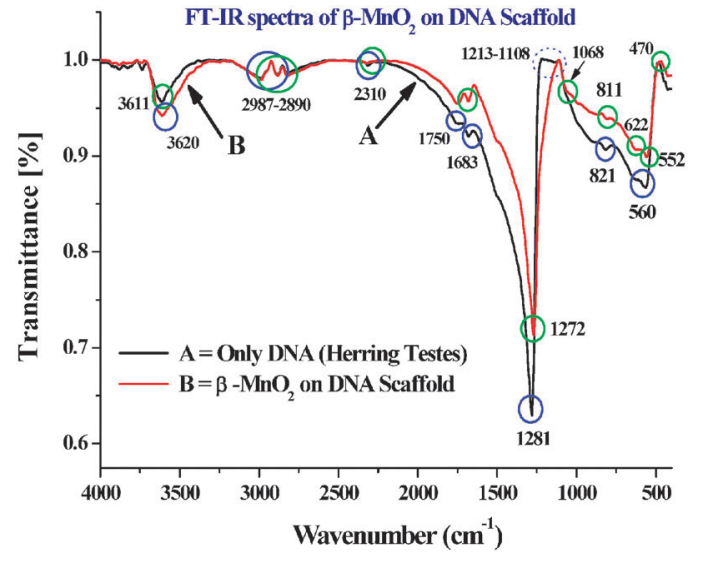

Fig. 6 The Fourier transform infrared (FTIR) spectra of bare DNA (curve A) and DNA-bound $\beta-\mathrm{MnO}_{2}$ nanomaterials (curve $\mathrm{B}$ ) having the flake-like shape at a wavelength scale of 4000 to $400 \mathrm{~cm}^{-1}$.

nanomaterials; this indicates the interaction of $\mathrm{MnO}_{2}$ with the phosphate group in DNA. Three prominent peaks for DNA appeared at 552, 622 and $811 \mathrm{~cm}^{-1}$ in the $\mathrm{DNA}-\mathrm{MnO}_{2}$ sample in spectrum B. The wavenumber region $1390-1750 \mathrm{~cm}^{-1}$ is the stretching vibration due to the carbonyl mode. In that region two sharp peaks at $1683 \mathrm{~cm}^{-1}$ and $1750 \mathrm{~cm}^{-1}$ are observed only for DNA samples are due to carbonyl group stretching vibration, whereas both the peaks are shifted in case of DNA-bounded $\mathrm{MnO}_{2}$ samples. In both the samples, a weak but prominent peak appeared at $2310 \mathrm{~cm}^{-1}$ which is due to the DNA molecule only. A sharp stretching vibration that appeared in both the samples in the range $2987-2890 \mathrm{~cm}^{-1}$ is due to the stretching vibration of $\mathrm{C}-\mathrm{H}$ bonds in $-\mathrm{CH}_{2}$ group, which again proves the presence of DNA with $\mathrm{MnO}_{2}$ particles. A sharp band appeared at $3611 \mathrm{~cm}^{-1}$ only for DNA. which is shifted to $3620 \mathrm{~cm}^{-1}$ for DNA-bounded $\mathrm{MnO}_{2}$; this is due to the $\mathrm{OH}$ group in the DNA molecule. The absorption peak that appeared near $422 \mathrm{~cm}^{-1}$ to $470 \mathrm{~cm}^{-1}$ is assigned to the Mn-O stretching vibration of the $\beta-\mathrm{MnO}_{2}$. Pal et al. ${ }^{29}$ observed $\mathrm{Mn}-\mathrm{O}$ bond vibration near $420-433 \mathrm{~cm}^{-1}$ for their study on $\beta-\mathrm{MnO}_{2}$. Sangwan et al. ${ }^{40 a}$ and others ${ }^{40 b, c}$ observed $\mathrm{Mn}-\mathrm{O}$ bond vibration at 515 and $480 \mathrm{~cm}^{-1}$ for their study on $\mathrm{MnO}_{2}$ nanomaterials. The experimentally observed FTIR bands of herring testes DNA with corresponding peak assignments and their comparison with the reported value ${ }^{41}$ are elaborated in Table T-1 (ESI $\dagger$ ). The above FTIR analysis confirmed that the phosphate backbone and the carbonyl moiety of DNA mainly interact and assist the binding of $\mathrm{MnO}_{2}$ particles with DNA molecules.

\section{Reaction mechanisms for the formation $\beta-\mathrm{MnO}_{2}$ nanomaterials on the DNA scaffold}

Shape-selective $\beta-\mathrm{MnO}_{2}$ nanomaterials were synthesized by reaction of $\mathrm{MnCl}_{2}$ with $\mathrm{NaOH}$ in presence of DNA with continuous stirring for about 2 hours at RT. The shapes of the different $\mathrm{MnO}_{2}$ particles formed are given in Table 1. In our reaction, the presence of both DNA and $\mathrm{NaOH}$ were extremely important for the formation of differently shaped $\mathrm{MnO}_{2}$ particles. When we carried out the reaction with $\mathrm{Mn}$ (II) salt and $\mathrm{NaOH}$ only, 
the particles were formed and precipitated after their formation because of the absence of any stabilizing agent. In the absence of $\mathrm{NaOH}$, but the presence of $\mathrm{Mn}$ (II) salt and DNA, no $\mathrm{MnO}_{2}$ particles were formed during the experimental time scale. Thus, the presence of all the reagents in proper concentration is extremely important for the generation of specifically shaped $\beta-\mathrm{MnO}_{2}$ nanomaterials in our prescribed procedure. In the reaction, initially after the addition of $\mathrm{Mn}$ (II) salt with DNA, a slight color change observed (clear solution to opaque) was due to the interaction of positively charged Mn(II) ions with the negatively charged phosphate functional group of the DNA molecule. We believed that the $\mathrm{Mn}^{2+}$ ions were adsorbed on the phosphate group of the DNA, which was further confirmed by the shifting of UV-Vis absorption band for the mixed solution compared with pure DNA, as seen in Fig. 1. After the addition of $\mathrm{NaOH}$ during stirring, the solution was initially pale white brown in colour, which turned into dark brown indicating the completion of the reaction. The pale white brown colour was because of the formation of $\mathrm{Mn}(\mathrm{OH})_{2}$ and the dark brown colour at the end of the process was because of the $\mathrm{MnO}_{2}$ particles. The most probable mechanism of our reaction is given below:

$$
\begin{gathered}
\mathrm{MnCl}_{2}+2 \mathrm{NaOH}=\mathrm{Mn}^{2+}(\mathrm{aq})+2 \mathrm{OH}^{-}(\mathrm{aq})+2 \mathrm{NaCl} \\
\mathrm{Mn}^{2+}(\mathrm{aq})+2 \mathrm{OH}^{-}(\mathrm{aq}) \rightarrow \mathrm{Mn}(\mathrm{OH})_{2} \text { (opaque) } \\
\mathrm{Mn}(\mathrm{OH})_{2} \rightarrow \mathrm{MnO}_{2}+2 \mathrm{H}^{+}+2 \mathrm{e}^{-} \\
\mathrm{Mn}(\mathrm{OH})_{2}+1 / 2 \mathrm{O}_{2} \rightarrow \mathrm{MnO}_{2}+\mathrm{H}_{2} \mathrm{O} \text { (dark brown) }
\end{gathered}
$$

Thus, during the course of the reaction the $\mathrm{MnO}_{2}$ nuclei were formed and grew onto the DNA already present in the solution; that generated the different morphology. From the FTIR analysis, we observed that mainly the phosphate group and the deoxyribose parts of the DNA were bounded with $\mathrm{MnO}_{2}$ and control their specific growth. As discussed earlier, the $\mathrm{Mn}^{2+}$ ions were electrostatically bound with the negatively charged phosphate backbone of DNA and generated a $\mathrm{Mn}^{2+}$-DNA complex, which then reacted with the $\mathrm{NaOH}$ and initially generated the $\mathrm{Mn}(\mathrm{OH})_{2}$. It was then oxidized in presence of atmospheric oxygen to $\mathrm{MnO}_{2}$ particles. Thus the $\mathrm{MnO}_{2}$ nuclei initially formed grew onto the DNA and generated the different morphology. It was observed that when the DNA concentration was lower, the $\mathrm{MnO}_{2}$ particles grew uniformly into a helical DNA structure and generated the wire-like morphology, as seen in the TEM image in Fig. 2. When the DNA concentration was higher, the $\mathrm{MnO}_{2}$ particles were found to be aggregated or agglomerated to form the flake-like structure, also seen in the TEM image in Fig. 2. Therefore, we believed that the DNA molecules bound at the surface of the $\mathrm{MnO}_{2}$ particles and stabilized them. It is known that functional groups, such as the phosphate group, preferably bind to the metal and metal oxide surfaces. Zhu et al. previously reported that DNA with $\mathrm{P}=\mathrm{O}$ and $\mathrm{C}-\mathrm{O}-\mathrm{P}$ groups could effectively bind to the surface of the $\mathrm{TiO}_{2}$ nanomaterials via chemical adsorption. ${ }^{42}$ It is important to note that the synthesized particles are stable for more than six months, while stored in a refrigerator in a sealed container. However, it is important to say that at this point we were not fully aware of the detailed mechanism for their specific formation of different shapes and the binding with specific functional group. Further study is necessary to confirm the clear mechanism of the formation of different morphologies. The synthesized $\beta-\mathrm{MnO}_{2}$ nanomaterials were successfully utilized for two different applications: one is the organic catalytic reaction for the spontaneous polymerization of aniline hydrochloride to emeraldine salt (polyaniline); and other is the electrochemical supercapacitor study, as will be discussed below.

\section{Catalytic application of DNA-encapsulated $\beta-\mathrm{MnO}_{2}$ nanomaterials for the polymerization of aniline hydrochloride to emeraldine salt (polyaniline)}

Polyaniline (PANI) is one of the most studied conductive polymers because of its high electronic conductivity, redox and ion-exchange properties, excellent environmental stability and the ease of preparation from common chemicals. PANI has good potential for application because the mechanism of aniline oxidation has been studied for more than three decades. PANI is obtained in three different forms: the protonated emeraldine salt (green colour); the leucoemeraldine (white or colorless); and the pernigraniline (blue or violet). The different colors, charges and conformations with multiple oxidation states make PANI a potential material for various applications such as actuators, supercapacitors, corrosion inhibitors and electrochromics. Among the three forms of PANI, the emeraldine salt is a highly conductive organic polymer that is useful in many industrial applications such as supercapacitors, sensors and molecular electronics. The PANI synthesis includes two interrelated processes. In the course of polymerization, the monomer undergoes a chain reaction with the formation of regular macromolecules, and the growing chains are simultaneously organized into complex supramolecular structures. As a result, conductive polymers containing stable supramolecular structures with various morphologies are formed. Most of these structures cannot be dissolved or melted without the destruction of the polymer chains and changing the properties of the polymer. Thus, the synthesis of any of the forms of PANI is not an easy task and requires a longer time and harsh reduction conditions. For these reasons, it is generally important to develop an easy process to prepare the emeraldine salt at room temperature. Stejskal et al. prepared the emeraldine salt using ammonium peroxidisulfate as oxidizing agent. ${ }^{43}$ Taleghani et al. prepared emeraldine salt using $\mathrm{KIO}_{3}$ as oxidizing agent at room temperature under stirring for about 5 hours. ${ }^{44}$ Byoung-Jinkin et al. prepared the emeraldine salt using a polymer initiator around $200{ }^{\circ} \mathrm{C}$ for 12 hours. ${ }^{45}$ All these processes demand higher reaction temperatures and longer times to get the desired product. In the past few years, it was observed that metal and metal oxide NPs can act as catalysts for different types of organic and inorganic chemical reactions, and that the catalysis reaction rate becomes faster compared with conventional chemical reactions. Among the different metal oxides, $\mathrm{MnO}_{2}$ shows great potential as an alternative material because it is cheap, abundant and environmentally friendly. Moreover, $\beta-\mathrm{MnO}_{2}$ is found to be 
useful in many organic catalytic reactions such as selective oxidation of allylic and benzylic hydroxyl groups to other carbonyl compounds, $\mathrm{C}-\mathrm{C}$ coupling reaction of $\beta$-naphthol into $2,2^{\prime}$ binol, one-pot conversion of alcohols into imines directly in presence of suitable amine, and one-pot conversion of alcohols directly into esters. But in most the cases, bulk $\mathrm{MnO}_{2}$ was used, and the reaction rate was slower and required a higher reaction temperature. In the present study, we checked the potential of our synthesized $\beta-\mathrm{MnO}_{2}$ particles for use as a catalyst for the polymerization of aniline hydrochloride to an emeraldine salt at room temperature. It is important to note that it is the first report where DNA encapsulated $\beta-\mathrm{MnO}_{2}$ has been used as a catalyst for the polymerization reaction described above. The probable chemical reaction that took place is shown below: of DNA. The reaction product was separated via centrifugation, washed with ethanol and water and finally dried for different characterizations and for application purposes. The formation of the product was confirmed from the UV-Vis, LASER Raman, FTIR and ${ }^{1} \mathrm{H}$ NMR studies. Fig. 7A shows the combined UV-Vis absorption spectra of the starting material and the product. Curve a shows the absorption band for aniline hydrochloride and curve $\mathrm{b}$ shows the absorption band of emeraldine salt. Aniline hydrochloride showed a peak at $247 \mathrm{~nm}$ due to an $n-\pi^{*}$ transition and also showed a high intense peak at lower wavelength side at $\sim 200 \mathrm{~nm}$ due to $\pi-\pi^{*}$ transitions. After mixing with $\beta-\mathrm{MnO}_{2}$ nanomaterials, the reaction generated the emeraldine salt, which shown in curve b in the UV-Vis spectra. In curve $b$, all the spectra that were present for aniline hydro-

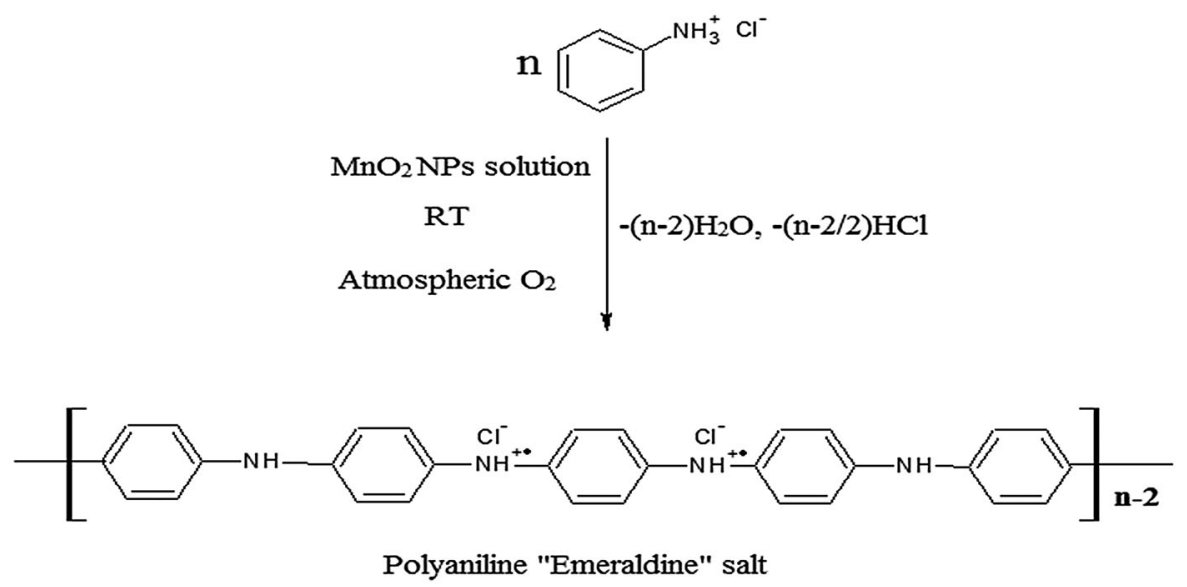

For the catalysis reaction, 0.1 (M) aniline hydrochloride solutions was mixed with a solution of DNA-encapsulated $\beta-\mathrm{MnO}_{2}$ nanomaterial at a very low concentration $(0.00273 \mathrm{M})$ and stirred continuously. Instantly, a bluish color solution appeared and turned into a green colored precipitate that indicated the formation of the PANI - 'emeraldine salt', one of the known forms of PANI. Actually, we observed the change in the color of the reaction mixture from colorless to green within a minute when the $\mathrm{MnO}_{2}$ NPs solution was added, even though the stirring was continued for 5 more minutes no significant color change was observed. Then, the whole solution mixture was centrifuged, and the solid mass was separated. We did several control experiments to check the potential of $\beta-\mathrm{MnO}_{2}$ nanomaterials as catalysts and examined the reaction without $\beta-\mathrm{MnO}_{2}$ nanomaterials, but only with DNA solution and $\mathrm{NaOH}$ solution separately for the same reaction. There was neither color change nor any indication of the emeraldine salt formation within our experimental time scale, which confirmed the necessity of $\beta-\mathrm{MnO}_{2}$ nanomaterials as catalysts. Moreover, we have examined the catalysis reaction with $\beta-\mathrm{MnO}_{2}$ nanomaterials (spherical shape) ${ }^{29}$ synthesized in sodium dodecyl benzene sulfonate (SDBS) micellar media and observed that the catalysis reaction was slower as compared to our catalyst. The better catalytic activity of DNA-capped $\beta-\mathrm{MnO}_{2}$ is probably because of the faster electron transfer due to the particles' specific morphology (wire or flake-like shapes) in the presence chloride are present and in addition three new peaks appeared one at $279 \mathrm{~nm}$, and two broad peaks near 400 and $720 \mathrm{~nm}$. These bands appeared because of the formation of the reaction product emeraldine salt in the reaction medium. It is given in literature that the bands appearing at 300-350 nm show a $\pi-\pi^{*}$ transitions of benzenoid rings; the band at 400-450 nm shows polar $n-\pi^{*}$ transitions and the band at 500-750 nm shows $\pi-\pi^{*}$ transitions of quinone-imine groups. All these absorption bands observed in UV-Vis spectra belong to the characteristic emeraldine salt form of PANI. ${ }^{46,47}$ The inset of UV-Vis spectra shows the camera image of aniline hydrochloride (colorless) and emeraldine salt (green color). Fig. 7B shows the LASER Raman spectra of the emeraldine salt. The Raman peaks are observed at 1170, 1260, 1348, 1497, 1593 and $1760 \mathrm{~cm}^{-1}$. The Raman peak at $1170 \mathrm{~cm}^{-1}$ is attributed to $\mathrm{C}-\mathrm{H}$ bending of the quinoid ring, and the peak at $1260 \mathrm{~cm}^{-1}$ is attributed to the $\mathrm{C}-\mathrm{H}$ bending of the benzoid ring. The peak at $1348 \mathrm{~cm}^{-1}$ is attributed to the $\mathrm{C}-\mathrm{N}$ stretching of the radical cation, and the peak at $1497 \mathrm{~cm}^{-1}$ is the $\mathrm{C}=\mathrm{N}$ stretching of the quinoid ring of the emeraldine salt. All these peaks nicely match with the reported Raman spectra of the emeraldine salt. ${ }^{48}$ Fig. 7C shows the FTIR spectra of the emeraldine salt. The spectra were compared with the starting material aniline hydrochloride (not shown here). All the expected peaks appeared for emeraldine salt. The peak at $3432 \mathrm{~cm}^{-1}$ corresponds to $\mathrm{N}-\mathrm{H}$ stretching, and the peak at $1295 \mathrm{~cm}^{-1}$ corresponds to $\mathrm{C}-\mathrm{N}$ stretching. 
A
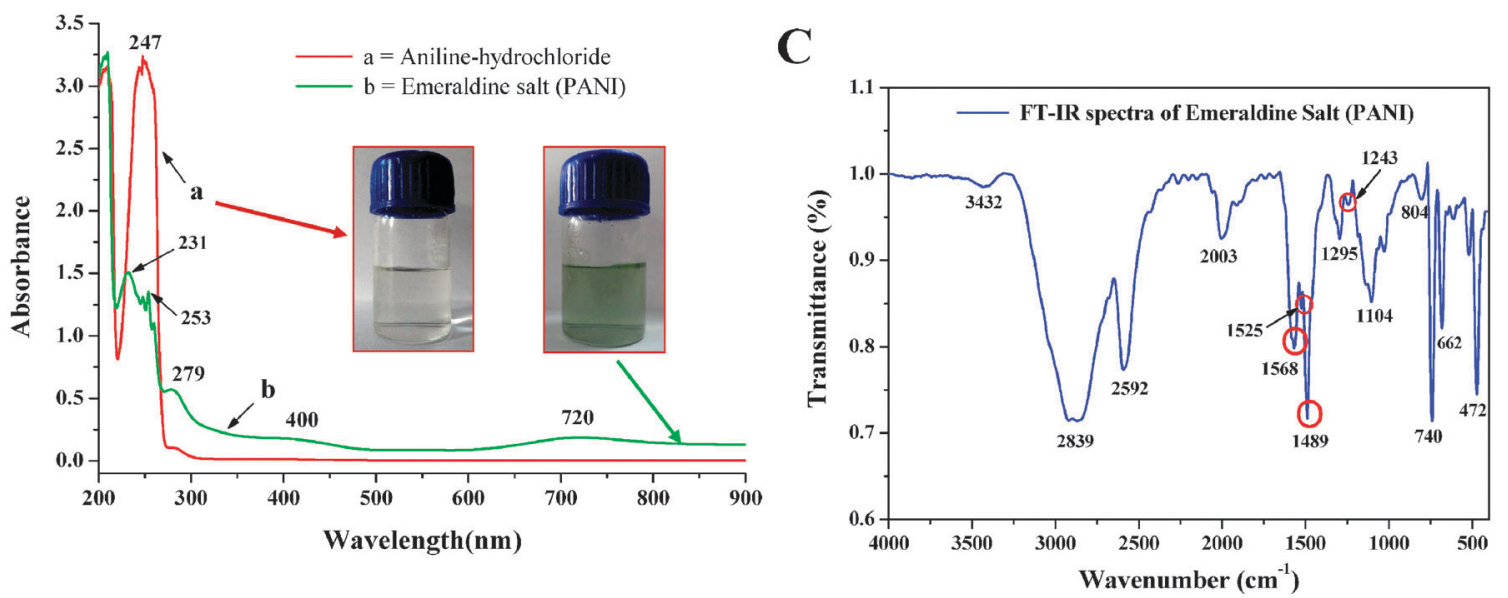

B
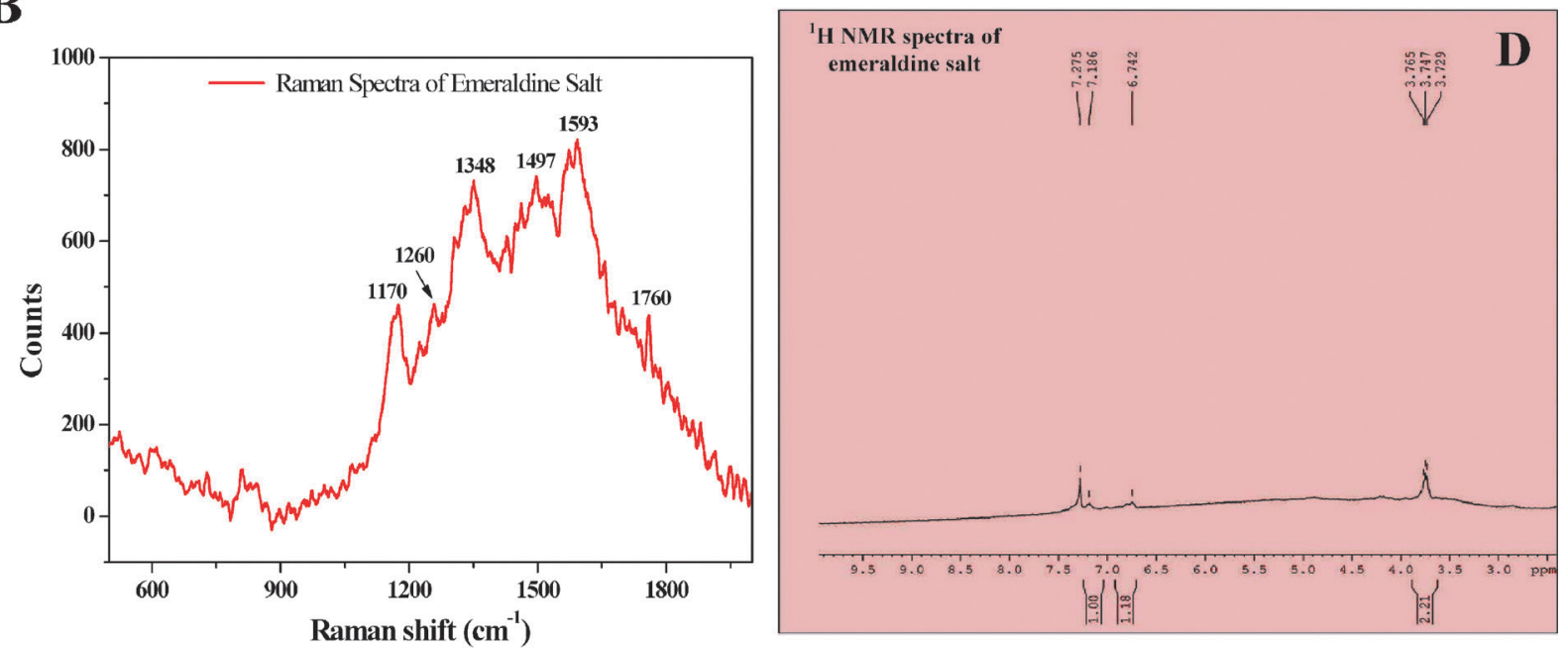

Fig. 7 Catalysis study using $\beta-\mathrm{MnO}_{2}$ nanomaterials on a DNA scaffold as catalyst. (A) UV-Vis spectra of aniline hydrochloride (curve a) and emeraldine salt (curve b). The inset shows the camera images of the aniline hydrochloride (colorless) and emeraldine salt (green color). (B), (C) and (D) are the LASER Raman, FTIR and ${ }^{1} \mathrm{H}$ NMR spectra of the emeraldine salt, respectively.

The peak at $804 \mathrm{~cm}^{-1}$ corresponds to the out-of-plane $\mathrm{N}-\mathrm{H}$ bending, and the peak at $2592 \mathrm{~cm}^{-1}$ corresponds to the $=\mathrm{C}-\mathrm{H}$ stretching of the aromatic ring. The band at $1104 \mathrm{~cm}^{-1}$ is attributed to the in-plane bending vibration due to the $\mathrm{C}-\mathrm{H}$ group that was formed during protonation. The peaks at $900-400 \mathrm{~cm}^{-1}$ correspond to the fingerprint region of the aromatic compounds. The peaks at $1568 \mathrm{~cm}^{-1}$ and $1489 \mathrm{~cm}^{-1}$ are characteristic of the quinoid of the emeraldine salt, and the peak at $1243 \mathrm{~cm}^{-1}$ corresponds to aromatic conjugation of the quinoid ring of the emeraldine salt, which is the characteristic of the conducting emeraldine salt. ${ }^{49,50}$ Thus, the FTIR analysis clearly shows the formation of an emeraldine salt. The formation of the product was further confirmed by ${ }^{1} \mathrm{H}$ NMR spectroscopy studies, as shown in Fig. 7D. From Fig. 7D, a broad peak at a $\delta$ value $3.72-3.37$ is due to the $\mathrm{N}-\mathrm{H}$ proton in the emeraldine salt, and the peaks at 6.74 , 7.12 and 7.27 are due to the protons attached to aromatic ring in the emeraldine salt. Thus, from the ${ }^{1} \mathrm{H}$ NMR study, we can conclude that there are two different chemically non-equivalent protons available: one from the quinoid and the other from benzenoid-like structures in the emeraldine salt. ${ }^{49,50}$ Finally, after centrifugation, the product (PANI) from the reaction mixture was separated and dried. We calculated the yield of the product from the calculated weight and observed weight, which was $\sim 82.5 \%$. All the above analyses confirmed the successful polymerization of the aniline hydrochloride to the emeraldine salt using $\beta-\mathrm{MnO}_{2}$ as catalyst. Finally, we examined the recyclability of the catalyst and found that the same catalyst can be reused 4-6 times without reduction of any catalytic activity, although the catalytic rate slowed after $6-8$ cycles because of the significant leaching of the catalyst.

\section{Electrochemical supercapacitor applications of the $\beta-\mathrm{MnO}_{2}$ nanomaterials on DNA scaffold}

The electrochemical performance of the as-prepared electrode materials were evaluated by cyclic voltammetry (CV) and galvanostatic charge-discharge techniques. Fig. 8a shows the CV curves of the wire-like and flake-like $\mathrm{MnO}_{2}$ electrodes at a scan rate of $5 \mathrm{mV} \mathrm{s}^{-1}$ in $1 \mathrm{M} \mathrm{Na}_{2} \mathrm{SO}_{4}$ electrolyte solution. Both the curves 
a

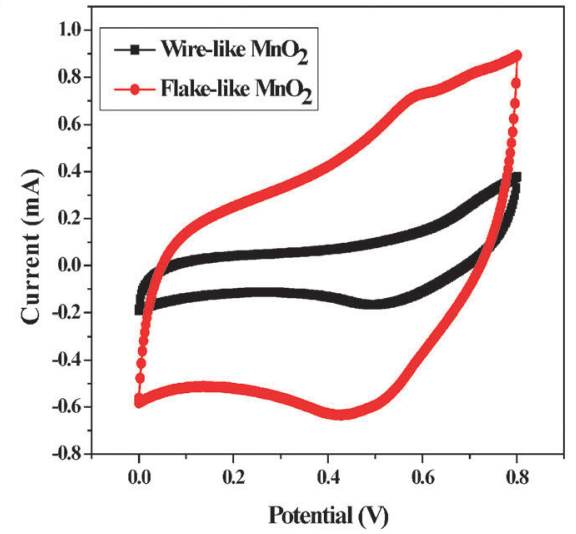

c

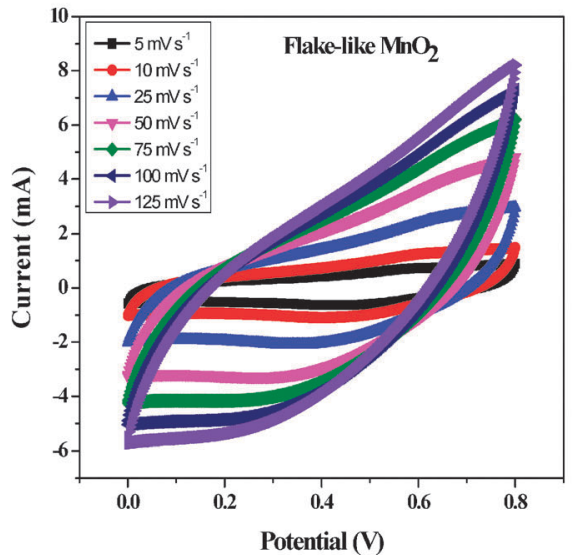

b

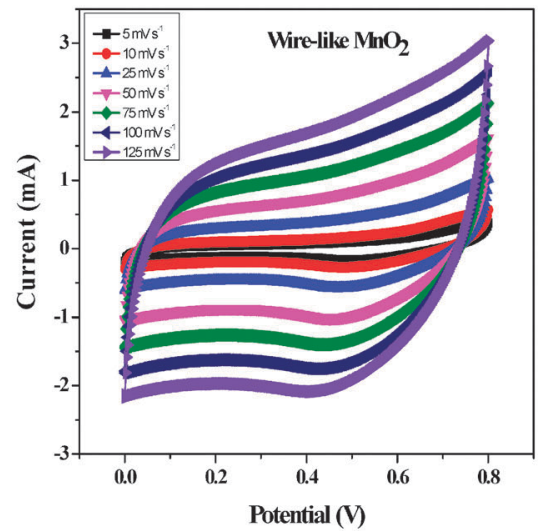

d

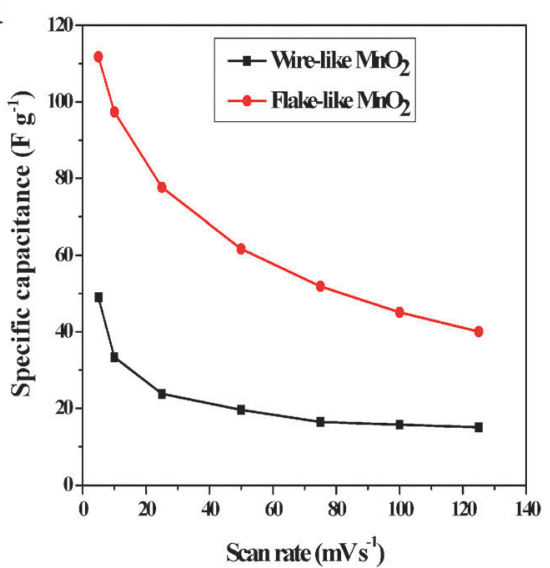

Fig. 8 (a) $\mathrm{CV}$ curves of wire-like and flake-like $\beta-\mathrm{MnO}_{2}$ nanomaterials on a DNA scaffold. The CV curves at different scan rates for wire-like (b) and flake-like (c) $\beta-\mathrm{MnO}_{2}$ nanomaterials electrodes. (d) Specific capacitance of the two $\mathrm{MnO}_{2}$ electrodes as a function of scan rate derived from their CV curves.

exhibited a pair of redox peaks (versus $\mathrm{Ag} / \mathrm{AgCl}$ ) at $0.4-0.6 \mathrm{~V}$, which correspond to the redox reaction of $\mathrm{Mn}(\mathrm{Iv}) / \mathrm{Mn}(\mathrm{III})$, associated with the insertion/extraction of the $\mathrm{Na}^{+}$ions, indicating the pseudo-capacitance behaviour. The proposed charged storage mechanism of the $\mathrm{MnO}_{2}$ surface was expressed as follows: ${ }^{51}$

$$
\left(\mathrm{MnO}_{2}\right)_{\text {surface }}+\mathrm{C}^{+}+\mathrm{e}^{-} \leftrightarrow(\mathrm{MnOOC})_{\text {surface }}
$$

where $\mathrm{C}^{+}\left(\mathrm{H}^{+}, \mathrm{Li}^{+}, \mathrm{Na}^{+}\right.$and $\left.\mathrm{K}^{+}\right)$denotes the protons and alkali metal cations in the electrolyte. Further, it could be observed from the $\mathrm{CV}$ curve that the integrated area of the flake-like electrode is larger than that of the wire-like $\mathrm{MnO}_{2}$ electrode, indicating the higher specific capacitance. Fig. $8 \mathrm{~b}$ and c illustrates CV curves of the wire-like and flake-like $\mathrm{MnO}_{2}$ electrodes at various scan rates from $5 \mathrm{mV} \mathrm{s}^{-1}$ to $125 \mathrm{mV} \mathrm{s}^{-1}$. All the curves exhibit almost the same shape even at higher scan rates, indicating the better electrochemical activity of the electrodes. With the increasing scan rates, the current response also increased. Fig. $8 \mathrm{~d}$ shows the specific capacitance variation of the wire-like and flake-like $\mathrm{MnO}_{2}$ electrodes at different scan rates. The specific capacitance of the wire-like $\mathrm{MnO}_{2}$ electrode was 50, $33,24,20,17,16$ and $15 \mathrm{~F} \mathrm{~g}^{-1}$ at scan rates of 5, 10, 25, 50, 75, 100 and $125 \mathrm{mV} \mathrm{s}^{-1}$, respectively. In contrast, the specific capacitance of the flake-like $\mathrm{MnO}_{2}$ electrode was 112, 97, $78,62,52,45$ and $40 \mathrm{~F} \mathrm{~g} \mathrm{~g}^{-1}$ at scan rates of $5,10,25,50,75$,
100 and $125 \mathrm{mV} \mathrm{s}^{-1}$, respectively. The specific capacitance of the electrodes decreased with increasing scan rate from 5 to $125 \mathrm{mV} \mathrm{s}^{-1}$. This may be due to the discrepant insertion/ extraction behaviors of the $\mathrm{Na}^{+}$ion from the electrolyte to the electrode surface at higher scan rates. At lower scan rates, the diffusion of the ions from the electrolyte can access almost all the available pores of the electrode surface, resulting in a higher specific capacitance. With increasing scan rates, the effective interaction between the ions and the electrode was reduced, which resulted a significant reduction in capacitance values. $^{52,53}$ In our present work, the flake-like $\beta-\mathrm{MnO}_{2}$ electrode delivered a maximum capacitance of $112 \mathrm{~F} \mathrm{~g}^{-1}$ and for the wirelike $\beta-\mathrm{MnO}_{2}$ is $50 \mathrm{~F} \mathrm{~g}^{-1}$ at $5 \mathrm{mV} \mathrm{s}^{-1}$. The observed capacitance is higher than the previously reported $\beta-\mathrm{MnO}_{2}$, which is $9 \mathrm{~F} \mathrm{~g}^{-1}$ and $57.7 \mathrm{~F} \mathrm{~g}^{-1}$ in the two different reports. ${ }^{54,55}$ The length and diameter of the nano-flakes and nanowires are $\sim 275 \pm 25 \mathrm{~nm}$ and $\sim 25 \pm 5 \mathrm{~nm} ; \sim 1.9 \pm 0.2 \mu \mathrm{m}$ and $\sim 35 \pm 5 \mathrm{~nm}$. The flakelike structure showed higher capacitance compared to the wirelike structure, which is because of the small length and diameter of the nano-flakes; this provides a high surface area and short diffusion path lengths, finally facilitating the efficient electron/ion transport to enhance the specific capacitance. Further, the $\mathrm{CV}$ curves showed a pair of redox peaks at 0.4-0.6 V (versus $\mathrm{Ag} / \mathrm{AgCl})$, which correspond to the redox reaction between 
Mn(IV) and Mn(III), associated with the insertion/extraction of the $\mathrm{Na}^{+}$ions and indicating the pseudo-capacitance behavior. According to many reported studies, no such peaks related to a redox reaction of different phases of the $\mathrm{MnO}_{2}$ have been ever observed when the same $\mathrm{Na}_{2} \mathrm{SO}_{4}$ is used as electrolyte. ${ }^{56}$ The existence of the redox peaks suggests that the charge storage mechanism is mainly based of a redox reaction. $\beta-\mathrm{MnO}_{2}$ provide only a surface faradic reaction (pseudocapacitance). ${ }^{57}$

Galvanostatic charge-discharge (GCD) measurements were performed to evaluate the supercapacitive performance of the $\mathrm{MnO}_{2}$ nanostructure electrodes for practical application. Fig. 9a displays the GCD curves of the wire-like and flake-like $\mathrm{MnO}_{2}$ electrodes at a current density of $0.1 \mathrm{~mA} \mathrm{~cm}{ }^{-2}$ in $1 \mathrm{M} \mathrm{Na}_{2} \mathrm{SO}_{4}$ solution. Both the curves exhibited the symmetric triangle shape. Unlike the linear characteristic of an ideal capacitor electrode, the small-sloped potential plateaus in the charge and discharge curves revealed the pseudocapacitive behavior of the $\mathrm{MnO}_{2}$. Fig. 9b and c displays the GCD curves of the wire-like and flake-like $\mathrm{MnO}_{2}$ electrodes between 0 and $0.8 \mathrm{~V}$ at various current densities. The good symmetry behavior of the GCD curves demonstrates the good reversibility of the reaction for charge-discharge. Further, the calculated specific capacitance of the wire-like and flake-like $\mathrm{MnO}_{2}$ electrodes from the GCD curves were 25 and $69 \mathrm{~F} \mathrm{~g}^{-1}$ at $0.1 \mathrm{~mA} \mathrm{~cm}^{-2}$, respectively. When the current density was increased to $1 \mathrm{~mA} \mathrm{~cm}{ }^{-2}$, the specific capacitance of the flake-like $\mathrm{MnO}_{2}$ electrode maintained at $37 \mathrm{~F} \mathrm{~g}^{-1}$.
The results indicate that the flake-like $\mathrm{MnO}_{2}$ electrode displays good rate capability at a higher current density.

The cycling stability of a supercapacitor is another key factor determining its long-term application. The cycling performances of the electrodes were measured by repeating CV measurements at $125 \mathrm{mV} \mathrm{s}^{-1}$ for 4000 cycles. Fig. 9d shows the capacitance retention curves of the wire-like and flake-like $\mathrm{MnO}_{2}$ electrodes. The flake-like $\mathrm{MnO}_{2}$ nanostructure exhibited excellent long-term stability, retaining $81 \%$ of the initial capacitance even after 4000 cycles. However, the capacitance retention of the wire-like $\mathrm{MnO}_{2}$ nanostructure electrode decreased, and the retention value was only $70 \%$ over 4000 cycles. Electrochemical impedance spectroscopy (EIS) measurements were performed to further evaluate the electrochemical performance of the as-prepared $\mathrm{MnO}_{2}$ electrodes. Nyquist plots of the wire-like and flake-like $\mathrm{MnO}_{2}$ electrodes before and after a 4000 cycling test are shown in Fig. 9e and f. All the EIS spectra exhibited an approximate semi-circle in the high-frequency region and a straight line in the low-frequency region. A straight line inclined at an angle between $45^{\circ}$ and $90^{\circ}$ to the real axis at the low-frequency region indicates the Warburg impedance, which represents the diffusive behaviors of the electrolyte in electrode pores and ions in electro-active materials. ${ }^{58}$ The semi-circle arc at the high frequency region was related to the charge transfer resistance $\left(R_{\mathrm{ct}}\right)$ between the electrode surface and electrolyte. The $R_{\text {ct }}$ values of the wire-like and flake-like $\mathrm{MnO}_{2}$ electrodes before the cycle test were 20 and $17 \Omega$, respectively. After 4000 cycles, a slight a

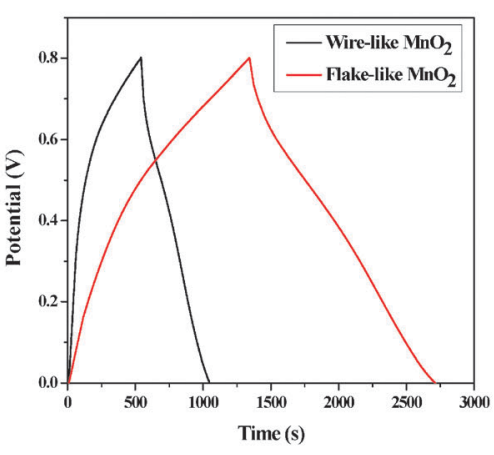

c

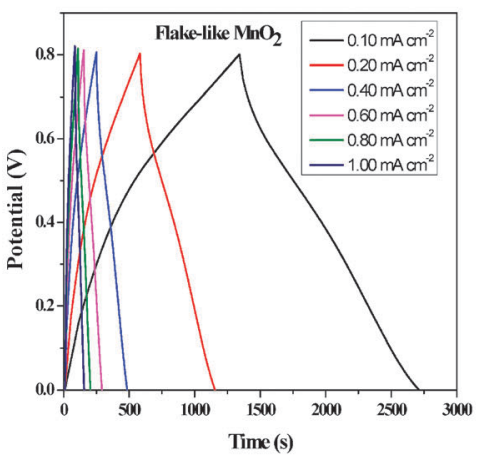

b

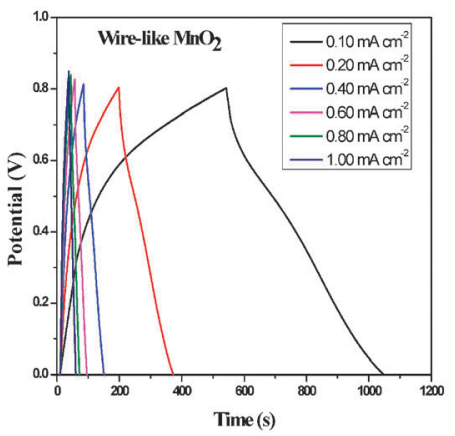

d

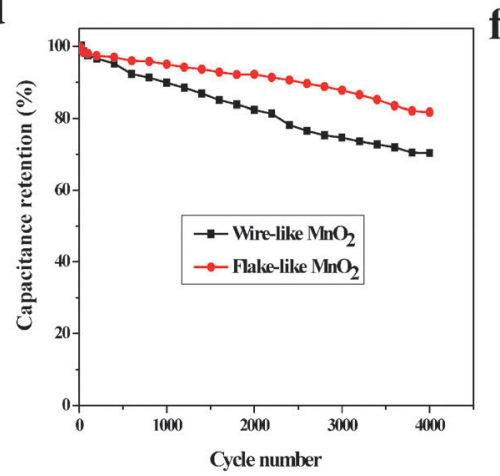

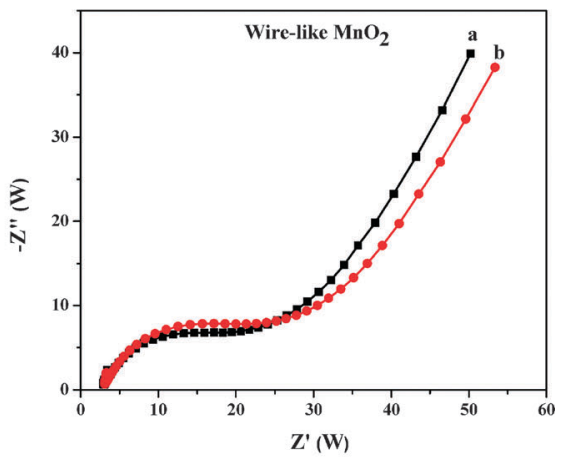

f

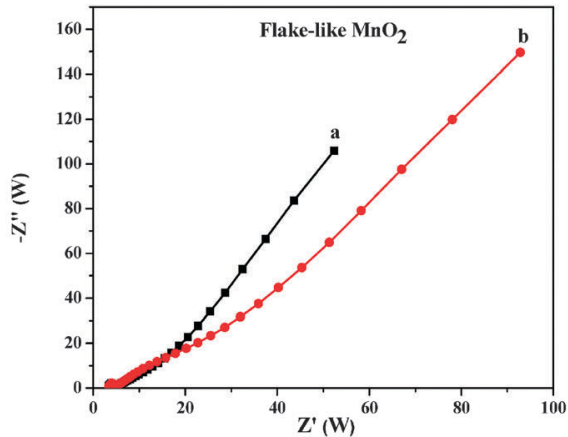

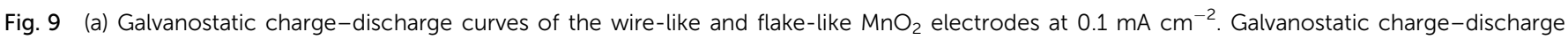

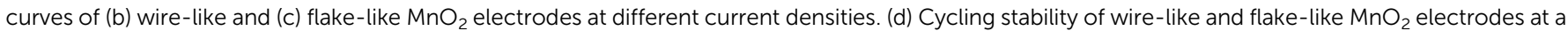

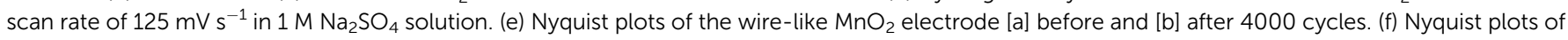
the flake-like $\mathrm{MnO}_{2}$ electrode [a] before and [b] after 4000 cycles. 
increase in the $R_{\mathrm{ct}}$ value was observed for both the electrodes (wire-like $\mathrm{MnO}_{2}=30 \Omega$ and flake-like $\mathrm{MnO}_{2}=22 \Omega$ ), which may be because of the loss of adhesion between the electroactive material and the current collector. These results demonstrate that the $\mathrm{MnO}_{2}$ electrodes possess better conductivity and are more suitable for charge transfer.

\section{Conclusion}

A DNA-assisted new approach is developed for the aqueous phase formation of the flake-like and wire-like $\beta-\mathrm{MnO}_{2}$ nanomaterials at room temperature within a shorter time scale. The $\beta-\mathrm{MnO}_{2}$ nanomaterials having a band gap energy $\sim 3.54 \mathrm{eV}$ are synthesized by the reaction of $\mathrm{Mn}$ (II) salt with $\mathrm{NaOH}$ in the presence of DNA under continuous stirring. The eventual diameter of the $\mathrm{MnO}_{2}$ particles in the wires or flakes and their length can be controlled by changing the DNA to Mn(II) salt molar ratio and by controlling other reaction parameters. The synthesized $\beta-\mathrm{MnO}_{2}$ nanomaterials exhibit pronounced catalytic activity in an organic catalysis reaction for the spontaneous polymerization of aniline hydrochloride to emeraldine salt (PANI) at room temperature and also act as a suitable positive electrode material in electrochemical supercapacitor applications. From the electrochemical experiment, it was observed that the $\beta-\mathrm{MnO}_{2}$ nanomaterials showed different specific capacitance $\left(C_{\mathrm{s}}\right)$ values for the flake-like and wire-like structures and that the $C_{\mathrm{s}}$ values are $112 \mathrm{~F} \mathrm{~g}^{-1}$ and $50 \mathrm{~F} \mathrm{~g}^{-1}$, respectively. The long-term cyclic stability study reveals that the flake-like $\mathrm{MnO}_{2}$ electrode shows excellent long-term stability and retains $c a .81 \%$ of the initial $C_{\mathrm{s}}$ even after 4000 cycles. In the future, the present approach can be extended to the generation of other oxide-based materials using DNA as a promising scaffold; it can also be used in different applications such as homogeneous and heterogeneous organic catalysis reactions, Li-ion battery materials or for the fabrication of other high performance energy storage devices.

\section{Acknowledgements}

Support from the Central Instrumental Facility (CIF) and help from Mr A. Rathishkumar (TEM in-charge, CIF), Mr R. Ravishankar and Mr J. Kennedy (SEM in-charge, CIF), CSIR-CECRI, Karaikudi are greatly appreciated. S. R. Ede and S. Anantharaj wish to acknowledge the council of scientific and industrial research (CSIR) for JRF fellowship and U. Nithiyanantham wishes to thank CSIR-CECRI for research-intern fellowship. S. Kundu wishes to acknowledge CSIR-CECRI for start-up research funding (Project number IHP 0067, DU No 5, old number OLP-0067). S. Kundu also wishes to thank Dr Vijayamohanan K. Pillai, Director and Dr M. Jayachandran, HOD, ECMS Division, CSIR-CECRI for their continuous support and encouragement.

\section{References}

1 S. Kundu, Phys. Chem. Chem. Phys., 2013, 15, 14107.

2 G. Kimuraa and K. Yamada, Synth. Met., 2009, 159, 914.

3 S. Kundu and H. Liang, Adv. Mater., 2008, 20, 826.
4 Y. N. Xia and N. J. Halas, MRS Bull., 2005, 30, 338.

5 B. O'Regan and M. Grätzel, Nature, 1991, 353, 737.

6 Z. Li, Y. Ding, Y. Xiong and Y. Xie, Cryst. Growth Des., 2005, 5, 1953.

7 Q. Li, J. B. Olson and R. M. Penner, Chem. Mater., 2004, 16, 3402.

8 D. Zheng, S. Sun, W. Fan, H. Yu, C. Fan, G. Cao, Z. Yin and X. Song, J. Phys. Chem. B, 2005, 109, 16439.

9 V. Subramanian, H. Zhu, R. Vajtai, P. M. Ajayan and B. Wei, J. Phys. Chem. B, 2005, 109, 20207.

10 F. Cheng, J. Zhao, W. Song, C. Li, H. Ma, J. Chen and P. Shen, Inorg. Chem., 2006, 45, 2038.

11 X. Wang and Y. Li, J. Am. Chem. Soc., 2002, 124, 2880.

12 T. Scheibel, R. Parthasarathy, G. Sawicki, X. M. Lin, H. Jaeger and S. L. Lindquist, Proc. Natl. Acad. Sci. U. S. A., 2003, 100, 4527.

13 S. W. Lee, C. B. Mao, C. E. Flynn and A. M. Belcher, Science, 2002, 296, 892.

14 A. P. Alivisatos, K. P. Johnsson, X. Peng, T. E. Wilson, C. J. Loweth, M. P. Bruchez Jr and P. G. Schultz, Nature, 1996, 382, 609.

15 M. R. Jones, R. J. Macfarlane, B. Lee, J. Zhang, K. L. Young, A. J. Senesi and C. A. Mirkin, Nat. Mater., 2010, 9, 913.

16 A. V. Pinheiro, D. R. Han, W. M. Shih and H. Yan, Nat. Nanotechnol., 2011, 6, 763.

17 M. Zheng, A. Jagota, E. D. Semke, B. A. Diner, R. S. McLean, S. R. Lustig, R. E. Richardson and N. G. Tassi, Nat. Mater., 2003, 2, 338.

18 S. Kundu and M. Jayachandran, RSC Adv., 2013, 3, 16486.

19 D. Majumdar, A. Singha, P. K. Mondal and S. Kundu, ACS Appl. Mater. Interfaces, 2013, 5, 7798.

20 S. Kundu, K. Wang, D. Huitink and H. Liang, Langmuir, 2009, 25, 10146.

21 C. F. Monson and A. T. Woolley, Nano Lett., 2003, 3, 359.

22 D. Sarker and M. Mandal, J. Phys. Chem. C, 2012, 116, 3227.

23 S. Kundu, H. Lee and H. Liang, Inorg. Chem., 2009, 48, 121.

24 X. C. Song, Y. Zhao and Y. F. Zheng, Cryst. Growth Des., 2007, 7, 159.

25 D. W. Kim, S. G. Oh, S. C. Yi, S. Y. Bae and S. K. Moon, Chem. Mater., 2000, 12, 996.

26 S. Shukla, S. Seal, L. Ludwig and C. Parish, Sens. Actuators, $B, 2004,97,256$.

27 B. C. Kim, J. H. Lee, J. J. Kim and T. Ikegami, Mater. Lett., 2002, 52, 114.

28 K. Chen, Y. D. Noh, K. Li, S. Komarneni and D. Xue, J. Phys. Chem. C, 2013, 117, 10770.

29 S. Jana, S. Basu, S. Pande, S. K. Ghosh and T. Pal, J. Phys. Chem. C, 2007, 111, 16272.

30 H. Xia, Y. Wang, J. Lin and L. Lu, Nanoscale Res. Lett., 2012, 7, 33. 31 J.-G. Wang, Y. Yang, Z.-H. Huang and F. Kang, J. Mater. Chem., 2012, 22, 16943.

32 X. Li, G. Wang, X. Wang, X. Li and J. Ji, J. Mater. Chem. A, 2013, 1, 10103.

33 C. X. Guo, A. A. Chitre and X. Lu, Phys. Chem. Chem. Phys., 2014, 16, 4672 .

34 T. A. Ha, V. M. Tran and M. L. P. Le, Adv. Nat. Sci.: Nanosci. Nanotechnol., 2013, 4, 35004. 
35 A. K. Ramdoss, G.-S. Kim and S. J. Kim, CrystEngComm, 2013, 15, 10222.

36 W. R. Mason III and H. B. Gray, Inorg. Chem., 1968, 7, 55.

37 A. K. Sinha, M. Basu, M. Pradhan, S. Sarkar, Y. Negishi and T. Pal, J. Phys. Chem. C, 2010, 114, 21173.

38 S. Tsunekawa, T. Fukuda and A. Kasuya, J. Appl. Phys., 2000, 87, 1318.

39 X. Zheng, Y. Zhu, P. Gao, N. Li and W. Weppner, Int. J. Electrochem. Sci., 2012, 7, 516.

40 (a) H. Kumar, Manisha and P. Sangwan, Int. J. Chem. Chem. Eng., 2013, 3, 155; (b) L. Kang, M. Zhang, Z. H. Liu and K. Ooi, Spectrochim. Acta, Part A, 2007, 67, 864; (c) L. Li, Y. Pan, L. Chen and G. Li, Solid State Chem., 2007, 180, 2896.

41 X. Sun, C. Zheng, F. Zhang, Y. Yang, G. Wu, A. Yu and N. Guan, J. Phys. Chem. C, 2009, 113, 16002.

42 R. R. Zhu, S. L. Wang and R. Zhang, Chin. J. Chem., 2007, 25, 958.

43 J. Stejskal and R. G. Gilbert, Pure Appl. Chem., 2002, 74, 857.

44 H. G. Taleghani, M. Aleahmad and H. Eisazadeh, World Appl. Sci. J., 2009, 6, 1607.

45 B.-J. Kim, S.-G. Oh, M.-G. Han and S.-S. Im, Langmuir, 2000, 16, 5841.

46 J. Jang, J. Ha and B. Lim, Chem. Commun., 2006, 1622.
47 M. M. Sk and C. Y. Yue, J. Mater. Chem. A, 2014, 2, 2830.

48 M. Cochet, W. K. Maser, A. M. Benito, M. A. Callejas, M. T. Martínez, J.-M. Benoit, J. Schreiber and O. Chauvet, Chem. Commun., 2001, 1450.

49 M. Hatamzadeh, A. Mahyar and M. Jaymand, J. Braz. Chem. Soc., 2012, 23, 1008.

50 N. V. Blinova, J. Stejskal, M. Trchova, G. Marjanovic and I. Sapurina, J. Phys. Chem. B, 2007, 111, 2440.

51 W. Wei, X. Cui, W. Chen and D. G. Ivey, Chem. Soc. Rev., 2011, 40, 1697.

52 W. W. Liu, X. B. Yan and Q. J. Xue, J. Mater. Chem. C, 2013, 1, 1413.

53 A. Ramadoss and S. J. Kim, Carbon, 2013, 63, 434.

54 S. Devaraj and N. Munichandraiah, J. Phys. Chem. C, 2008, 112, 4406.

55 W. Yanmin, L. Haifeng, B. Mi, L. Binjia, S. Haifeng, W. Yanxuan and W. Fan, J. Alloys Compd., 2011, 509, 8306.

56 M. Liqiang, L. Han, Z. Yunlong, X. Lin, X. Xu, L. Yanzhu, Z. Zhengfei, K. Wang, N. Chaojiang and Z. Qingjie, Sci. Rep., 2013, 3, 1718.

57 W. Weifeng, C. Xinwei, C. Weixing and G. I. Douglas, Chem. Soc. Rev., 2011, 40, 1697.

58 J. Wang, Z. Gao, Z. Li, B. Wang, Y. Yan, Q. Liu, T. Mann, M. Zhang and Z. Jiang, J. Solid State Chem., 2011, 184, 1421. 